\title{
Article \\ Surfaceome Profiling of Rhabdomyosarcoma Reveals B7-H3 as a Mediator of Immune Evasion
}

\author{
Roxane R. Lavoie ${ }^{1}$, Patricio C. Gargollo ${ }^{1}$, Mohamed E. Ahmed ${ }^{1}$ (D), Yohan Kim ${ }^{1}$, Emily Baer ${ }^{1}$, Doris A. Phelps ${ }^{2}$, \\ Cristine M. Charlesworth ${ }^{3}$, Benjamin J. Madden ${ }^{3}$, Liguo Wang ${ }^{4}$, Peter J. Houghton ${ }^{2}$, John Cheville ${ }^{5}$, \\ Haidong Dong ${ }^{1,6}$, Candace F. Granberg ${ }^{1}$ and Fabrice Lucien ${ }^{1, * \mathbb{D}}$
}

check for

updates

Citation: Lavoie, R.R.; Gargollo, P.C.; Ahmed, M.E.; Kim, Y.; Baer, E.;

Phelps, D.A.; Charlesworth, C.M.;

Madden, B.J.; Wang, L.; Houghton,

P.J.; et al. Surfaceome Profiling of Rhabdomyosarcoma Reveals B7-H3 as a Mediator of Immune Evasion. Cancers 2021, 13, 4528. https:/ doi.org/10.3390/cancers13184528

Academic Editor: Saurabh Agarwal

Received: 29 June 2021

Accepted: 17 August 2021

Published: 9 September 2021

Publisher's Note: MDPI stays neutral with regard to jurisdictional claims in published maps and institutional affiliations.

Copyright: (C) 2021 by the authors Licensee MDPI, Basel, Switzerland. This article is an open access article distributed under the terms and conditions of the Creative Commons Attribution (CC BY) license (https:/ / creativecommons.org/licenses/by/ $4.0 /)$.
1 Department of Urology, Mayo Clinic, Rochester, MN 55902, USA; r.lavoie.roxane@mayo.edu (R.R.L.); gargollo.patricio@mayo.edu (P.C.G.); mohamed.ahmed@mayo.edu (M.E.A.); kim.yohan@mayo.edu (Y.K.); Emily.E.Baer@dmu.edu (E.B.); dong.haidong@mayo.edu (H.D.); granberg.candace@mayo.edu (C.F.G.)

2 Greehey Children's Cancer Research Institute, San Antonio, TX 78229, USA; PhelpsD@uthscsa.edu (D.A.P.); houghtonp@uthscsa.edu (P.J.H.)

3 Proteomic Core, Mayo Clinic, Rochester, MN 55902, USA; charlesworth.cristine@mayo.edu (C.M.C.); madden.benjamin@mayo.edu (B.J.M.)

4 Division of Computational Biology, Mayo Clinic, Rochester, MN 55902, USA; Wang.Liguo@mayo.edu

5 Department of Anatomic Pathology, Mayo Clinic, Rochester, MN 55902, USA; Cheville.John@mayo.edu

6 Department of Immunology, Mayo Clinic, Rochester, MN 55902, USA

* Correspondence: Lucien-Matteoni.Fabrice@mayo.edu

Simple Summary: Rhabdomyosarcoma (RMS) is the most common soft-tissue sarcoma in children, and there is a critical need to develop efficacious and tolerable anticancer therapies against this aggressive disease. To uncover druggable RMS-associated tumor antigens, we analyzed the cell surface protein repertoire in RMS tumor cells and normal tissue. We identified several surface proteins highly enriched in RMS, including the immune checkpoint molecule B7-H3. A further analysis using patient specimens showed that B7-H3 is overexpressed in most of RMS tumors and weakly or not detected in normal organs. Interestingly, we found that B7-H3 depletion was associated with higher immune cell killing activity against tumor cells. In line with this, high B7-H3 tumor expression was associated with lower CD8 T-cell density. Our study reveals novel RMS-associated proteins for the development of targeted therapies. In addition, we demonstrate that targeting B7-H3 function can pave the way for the design of new immunotherapies in the treatment of RMS.

Abstract: Novel therapeutic strategies are needed for the treatment of rhabdomyosarcoma (RMS), the most common soft-tissue sarcoma in children. By using a combination of cell surface proteomics and transcriptomic profiling of RMS and normal muscle, we generated a catalog of targetable cell surface proteins enriched in RMS tumors. Among the top candidates, we identified B7-H3 as the major immunoregulatory molecule expressed by RMS tumors. By using a large cohort of tissue specimens, we demonstrated that B7-H3 is expressed in a majority of RMS tumors while not detected in normal human tissues. Through a deconvolution analysis of the RMS tumor RNA-seq data, we showed that B7-H3-rich tumors are enriched in macrophages M1, NK cells, and depleted in CD8 ${ }^{+}-\mathrm{T}$ cells. Furthermore, in vitro functional assays showed that B7-H3 knockout in RMS tumor cells increases T-cell mediated cytotoxicity. Altogether, our study uncovers new potential targets for the treatment of RMS and provides the first biological insights into the role of B7-H3 in RMS biology, paving the way for the development of next-generation immunotherapies.

Keywords: rhabdomyosarcoma; targeted therapies; cell surface proteomics; B7-H3

\section{Introduction}

Rhabdomyosarcoma (RMS) is the most common childhood soft tissue sarcoma, with nearly $20 \%$ of patients presenting with locally aggressive and/or metastatic disease [1]. 
RMS is classified into two molecular subtypes based on the expression of the fusion gene $P A X 3 / 7$ FOXO1 [1,2]. Patients with fusion-positive RMS usually have a poorer outcome compared to fusion-negative RMS [3]. The PAX3/7-FOXO1 fusion protein drives an oncogenic transcriptional program, including the upregulation of genes involved in invasion, proliferation, and survival [4]. In contrast, fusion-negative RMS does not harbor PAX3/7FOXO1 fusion but a variety of mutations on oncogenes, including RAS, PIK3CA, FGFR4, and TP53 [5]. Multimodal therapies, including surgery, radiotherapy, and chemotherapy, have been the standard care for the treatment of RMS. The current chemotherapy regimens consist of combinations of Vincristine, Dactinomycin, and Cyclophosphamide and have shown to improve the survival rates by $60-90 \%$ in patients with localized disease [6-8]. In contrast, $90 \%$ of RMS-related deaths occur within two years following diagnosis and are mostly related to disease recurrence. Importantly, long-term effects and life-threatening complications often occur in the lifetime of RMS survivors $[9,10]$. This underscores the need for effective and more tolerable therapies for the treatment of RMS.

Antibody-based therapies, including immune checkpoint inhibitors, bispecific antibodies, antibody-drug conjugates, and CAR-T therapy, have transformed the therapeutic landscape of adult cancers [11]. Antibody-based therapies have a common denominator with the specific binding of a protein expressed on the surface of tumor cells. Cell surface proteins are ideal targets for anticancer therapies as their accessible extracellular domain makes pharmacological interventions more effective. To date, cell surface proteins account for $\sim 60 \%$ of all FDA-approved drugs [11]. Furthermore, it provides an alternative strategy to treat tumors with undruggable intracellular oncogenic alterations that drive transcriptional and translational programs, resulting in the aberrant expression of druggable cell surface proteins [12-14]. The surface proteome is composed of cell adhesion molecules; nutrients; metabolite transporters; immunoregulatory molecules; and growth factor receptors that control cancer cell behaviors, aggressiveness, and their response to therapy. The identification of tumor-associated surface proteins may provide important insights into tumor biology and be further exploited as therapeutic vulnerabilities.

In this study, we employed cell surface proteomics (surfaceomics) to establish a comprehensive map of cell surface proteins expressed in RMS. By integrating the transcriptomic data and proteomic data of RMS tumors and normal tissue, we revealed an RMS-specific cell surface protein signature. Among the top upregulated proteins, we identified B7$\mathrm{H} 3$ as the major immunoregulatory molecule expressed in RMS. We found that B7-H3 mediates tumor immune evasion through functional assays and transcriptomic characterization of the tumor immune landscape of RMS tumors. Our findings support B7-H3 as a therapeutic target for antibody-based therapies and provide new biological insights on its immunomodulatory role in RMS. Finally, this study demonstrates the potential of surfaceomics for cancer research and drug development.

\section{Materials and Methods}

\subsection{Cells and Reagents}

Human pediatric rhabdomyosarcoma cell lines SJCRH30 (RH30) (alveolar rhabdomyosarcoma (aRMS) fusion-positive, cat\# CRL-2061) and RD (embryonal RMS (eRMS), fusion-negative, cat\# CCL-136) were purchased from ATCC (Manassas, Virginia, USA). Two normal human skeletal muscle cell lines were purchased from Lonza (Basel Switzerland) (cat\#PCS-950-010) and ATCC (cat\#CC-2561). The RMS cell lines RH36 (fusion-negative) and RH18 (fusion-positive) were obtained from Dr. Peter Houghton. The RH30 cell line was grown in RPMI-1640 with 10\% FBS (Gibco, Waltham, MA, USA) and 1-mg/mL PenStrep (Gibco), the RD cell line was grown in DMEM with 10\% FBS (Gibco) and 1-mg/mL Pen-Strep (Gibco), and the normal muscle cell lines were cultured in HSkMC Growth Medium (Cell Applications, cat\#151-500, San Diego, CA, USA). The RMS-MC02 primary cells were isolated from a resected embryonal (fusion-negative) RMS tumor (IRB \#16006956) and cultured in DMEM-F12 (Gibco) with 10\% FBS (Gibco) and 1-mg/mL Pen-Strep (Gibco). The B7-H3 knockout RH30 cell line was generated using CRISPR/Cas-9 (Santa 
Cruz Biotechnology, sc-402032, Dallas, TX, USA), and negative selection was performed by flow cytometry using anti-B7H3 PE (DCN.70 clone, BioLegend, cat\#331606, San Diego, CA, USA). All cell lines were maintained in an incubator with a humidified atmosphere and $5 \%$ $\mathrm{CO}_{2}$ at $37^{\circ} \mathrm{C}$.

\subsection{Cell Surface Biotinylation and Mass Spectrometry}

A total of $5 \times 10^{7}$ cells from each cell line were subjected to cell surface biotinylation. EZ-Link-Sulfo-NHS-SS-biotin (Thermo Scientific, cat\#21331, San Diego, CA, USA) was added to cultured cells for $30 \mathrm{~min}$ at $4{ }^{\circ} \mathrm{C}$. The cells were washed with $50 \mathrm{mM}$ of glycine to quench the unbound biotin. The cells were lysed in NP-40 lysis buffer, and the biotinylated cell surface proteins were affinity-purified on streptavidin magnetic beads (Thermo Scientific, cat\#88816). After stripping off the nonspecifically bound proteins by several rounds of washing with the lysis buffer, the labeled proteins were reduced with $10-\mathrm{mM}$ TCEP (Thermo Scientific, cat\#77720) for $30 \mathrm{~min}$ at $50{ }^{\circ} \mathrm{C}$ and followed by alkylation with iodoacetamide (Thermo Scientific, 90034) for $30 \mathrm{~min}$ in the dark at room temperature. The proteins were run in a SDS-PAGE electrophoresis gel and submitted for mass spectrometry (additional information in the Supplementary Materials) [15-17].

\subsection{Bioinformatic Annotation of Cell Surface Proteins}

Genes encoding for the cell surface proteins were assembled from Gene Ontology GO:0005886 (plasma membrane) and UniProt using the keywords "homo sapiens" and "single-pass transmembrane domain" and "multi-pass transmembrane domain".

\subsection{Expression Analysis of RMS-Enriched Cell Surface Proteins in RMS Tumors and Normal Tissue}

The RNA sequencing data was processed and analyzed as previously reported [5] (GEO: GSE108022). The gene-level raw read counts matrix file was downloaded from the GEO database, and differential expression analyses were performed using DESeq2 [18]. Specifically, the DESeq2 default parameters/methods were used to estimate the size factors, estimate the dispersion, and perform the statistical tests. The cell surface proteins differently expressed between RMS $(n=101)$ and normal muscles $(n=5)$, fusion-negative $(n=66)$ and normal muscles, and fusion-positive $(n=35)$ and normal muscles with a fold change $\geq$ two and adjusted $p$-value $<0.05$ were undertaken for further analysis. To analyze the normal tissue expression of the RMS-enriched cell surface proteins, tissue-specific transcriptomes and proteomes were obtained from Jiang, $\mathrm{L}$ et al. that consisted of transcriptomic and proteomic analyses of 201 samples from 32 tissue types of 14 normal individuals [19]. The median relative protein and RNA abundances for each tissue type were transformed into absolute values (reversed $\log 2$ ) for further analysis. To identify the best therapeutic candidates, a composite ranking of the cell surface proteins was generated, where the cell surface proteins were ranked with equal weights based on their RNA and protein expression in the RMS tumors and normal tissue. For tumor expression, the genes and proteins were ranked from the most expressed to the least expressed. For normal expression, the genes and proteins were ranked from the least expressed to the most expressed.

\subsection{Deconvolution Analysis of Bulk RNA-seq}

From the GSE108022 RNA sequencing data, the genes with an average RPKM value across all samples less than 0.5 were removed, and then, the fraction of cell types (B cells, M1 macrophages, M2 macrophages, monocytes neutrophils, NK cells, CD4 T cells, CD8 $\mathrm{T}$ cells, Tregs, and dendritic cells) were identified and estimated using the QuanTIseq pipeline [20]. The RMS tumors were stratified by B7-H3 expression ( $25 \%$ highest and $25 \%$ lowest), and the immune cell abundance was compared between both groups.

\subsection{T-Cell Cytotoxicity Assay}

Adherent RH30 wild-type and B7-H3KO cells were plated in a 96-well plate and incubated $30 \mathrm{~min}$ at $37^{\circ} \mathrm{C}$ with calcein-AM (Biolegend, 425201). The cells were then 
washed twice with Live Cell Imaging Solution (Gibco, A14291DJ) and kept in RPMI-1640 (no phenol red) supplemented with 10\% HI-FBS. PBMC were isolated from the normal donor blood apheresis cones using a Ficoll gradient and activated overnight with $5 \mu \mathrm{g} / \mathrm{mL}$ of phytohemagglutinin (PHA-L; Millipore, cat\#431784, Burlington, MA, USA). PBMC were added to each well at a ratio 1:10 and 1:20 (Target:Effector). Each condition was performed in triplicate. The calcein fluorescence was recorded every $10 \mathrm{~min}$ for $16 \mathrm{~h}$ using the EVOS FL Auto (Thermo) system equipped with the onstage incubator set at $37^{\circ} \mathrm{C}$ and $5 \% \mathrm{CO}_{2}$. The total number of calcein-positive cells and fluorescence intensities of intracellular calcein were calculated for each condition. The tumor cell viability was calculated at $5 \mathrm{~h}$ postincubation. The survival index was obtained by the mean calcein fluorescence in treated cells divided by the mean fluorescence in the control (tumor cells only). An image analysis was performed using Fiji software (National Institute of Health, Bethesda, MD, USA).

\subsection{Statistical Analysis}

The normality of distribution was assessed using the Shapiro-Wilk normality test. The Student's $t$-test (parametric) and Mann-Whitney $U$ test (nonparametric) were employed to compare the two groups. A paired Wilcoxon test (Wilcoxon's signed rank test) was performed to analyze the data presented in Figure 6C. The results were considered significant for $p$-values $<0.05$. The $p$-values were either specified in the figure or denoted as asterisk: ${ }^{*} p<0.05,{ }^{* *} p<0.01$, and ${ }^{* *} p<0.001$. All data were analyzed and plotted in GraphPad Prism 9.0.1 (San Diego, CA, USA).

Additional materials and methods for the Western blot, immunohistochemistry, and flow cytometry can be found in the Supplementary Materials.

\section{Results}

\subsection{Identification of Cell Surface Protein Repertoires in RMS and Normal Muscle}

In order to define a set of cell surface proteins with an extracellular domain that can serve as potential therapeutic targets in RMS, we used a combination of cell surface capture and proteomic profiling on five RMS cell lines (three fusion-negative and two fusionpositive) and two normal skeletal muscle cell lines (Figure 1A). The proteins expressed in all fusion-negative and/or fusion-positive RMS cell lines by more than two-fold with a false discovery rate $<0.05$ compared to normal muscle were selected as target candidates. While the biotinylation method enriches for cell surface proteins, mass spectrometry can still reveal the cytosolic proteins interacting with plasma membrane proteins that are considered as "false" positives. To validate the subcellular location of the proteins identified, several publicly available databases were interrogated (Figure S1A). Gene Ontology GO:0005886 encompassed other annotation databases by providing the most exhaustive list of cell surface proteins. By using GO:0005886 for filtering data, we ensured not losing the true positives. An independent transcriptomic dataset (GSE108022) of 101 RMS (66 fusionnegative and 35 fusion-positive) and five normal skeletal muscle tissues was used to determine the expression profiles of the genes coding for cell surface proteins identified by mass spectrometry [5]. The publicly transcriptomic dataset Genotype-Tissue Expression (GTEx) containing gene expression profiles of 54 different human tissues from 948 donors was used to determine the expression of the target candidates in normal tissues. Finally, we also included the expression of target proteins obtained from a recent large-scale proteomic profiling of normal organs [19]. RNA and protein expression profiles in RMS and normal tissue were used to create a composite rank and identify targetable RMS-specific/enriched cell surface proteins. 
A

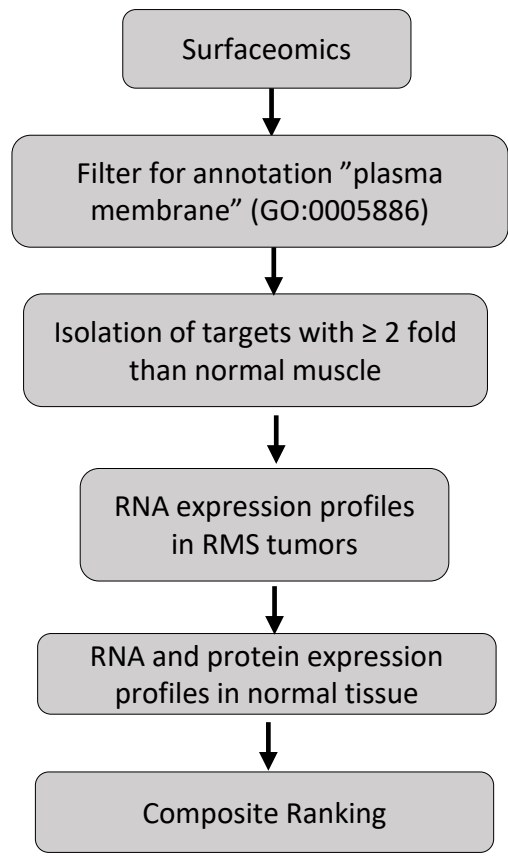

B

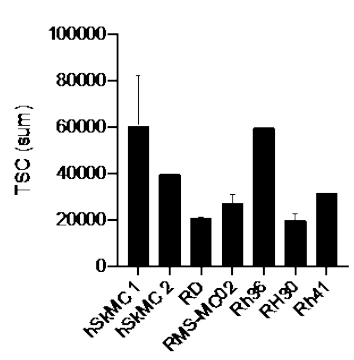

C<smiles>[C]1C#C[Si]1</smiles>

$\mathbf{E}$

Fusion Negative (3) $\quad$ Fusion Positive (2)

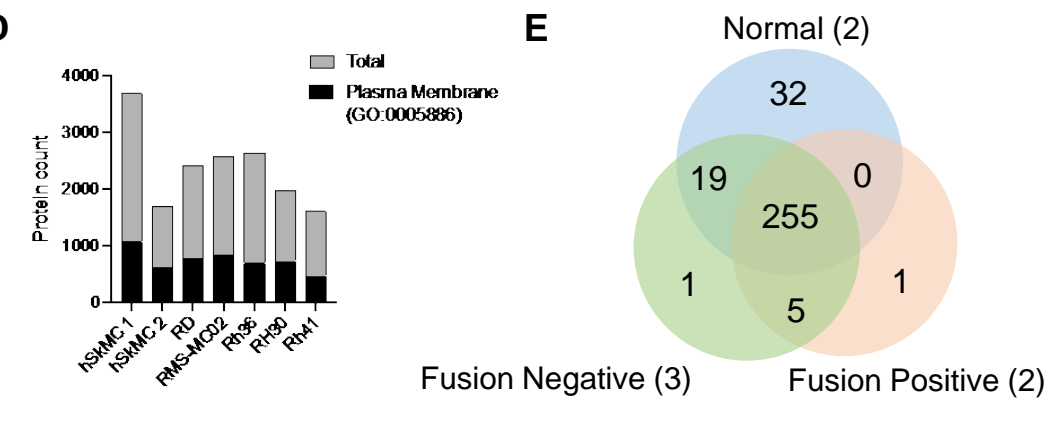

$\mathbf{F}$ $-2{ }^{0}{ }^{2}$

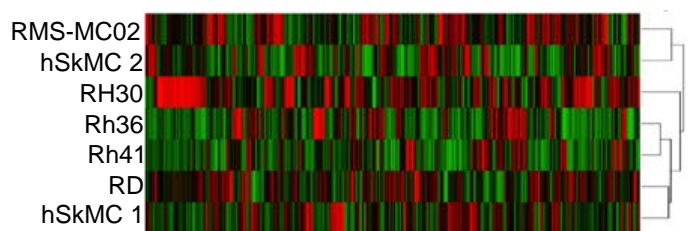

Figure 1. Distinct cell-surface protein signatures are identified in RMS subtypes and normal muscle. (A) Overall representation of the bioinformatics strategy to identify highly confident RMS-enriched cell surface proteins by combined proteomic and transcriptomic analysis of RMS. (B) Sum of TSC (total spectral count) and (C) NSAF (normalized spectral abundance factor) for each cell line analyzed. (D) Total protein count for each cell line. Count of proteins with the annotation plasma membrane is superimposed on the total protein count (black bars). (E) Venn diagram showing number of proteins identified in all cell lines of each subtype. (F) Heatmap of hierarchical clustering for cell surface protein data set filtered with the annotation "plasma membrane" (GO:0005886), Average linkage, Euclidean distance.

Upon an analysis of the cell surface proteome by label-free mass spectrometry, significant differences in the number of peptides (total spectral counts, TSC) were detected between individual samples (Figure 1B). To normalize our data, we employed a normalized spectral count by the protein length (NSAF), which improves the quantification of protein abundance with label-free proteomics. Upon applying NSAF, the total spectral counts were normalized, and no statistically significant differences the between samples were observed (Figure 1C). A total of 5061 different proteins were found in combined cell lines (Figure 1D). Protein identification revealed an average of 2676 proteins detected per cell line, with hSkMC1 showing the highest number of detected proteins (3694 proteins) (Table S1). From the pool of proteins identified by mass spectrometry, an average of 1455 proteins were located at the plasma membrane (Table S2). When the filtering step was applied with Gene Ontology GO:0005886 to tease out the proteins with incorrect subcellular locations, we found an average of $31.6 \%$ of the proteins annotated as located at the plasma membrane. The protein repertoires were heterogeneous within types of cell lines 
(Figures S1B-D and 1D). Despite sharing similarities, several proteins were found exclusively in one cell line compared to the other cell lines of the same group. When diseased and normal muscle-specific protein repertoires were compared, we identified a total of 255 proteins commonly expressed by the two normal skeletal muscle cell lines and the five RMS cell lines (Figure 1E). We found seven and 32 cell surface proteins specifically expressed by RMS cells and normal muscle cells, respectively. When the RMS cell lines were grouped based on their fusion status, only one protein was exclusively expressed in each RMS subtype. The unsupervised hierarchical clustering of the cell lines based on the protein repertoires showed four clusters (Figure 1F). The fusion-negative RMS cell lines RMS-MC02 and hSkMC1 segregated together, while the fusion-negative RMS cell lines RD and hSkMC2 clustered together. Fusion-positive RH41 and fusion-negative RH36 segregated together, and fusion-positive RH30 was separated from all other cell lines. The proteomic profiling of the RMS cell lines and normal skeletal muscle revealed cell type-specific surfaceome signatures, but it did not differentiate the RMS from normal muscle and fusion-positive from fusion-negative RMS cells.

\subsection{Validation of RMS-Enriched Cell Surface Proteins by Combined Proteomic and Transcriptomic Analysis}

The abundance of the cell surface proteins was compared between the normal muscle, fusion-negative, and fusion-positive RMS cell lines. A high degree of correlation in the protein expression was observed for the two normal skeletal muscle cell lines (Pearson's $r=0.7994 p<0.0001)$. Among the fusion-negative and fusion-positive cell lines, positive associations were also observed, but the correlation coefficients varied from 0.2829 (fusion-positive) to 0.4736 (fusion-negative) (Figure S1E). Among the cell surface proteins commonly expressed in fusion-negative and fusion-positive cell lines, 57 proteins were upregulated by more than two-fold in RMS compared to normal muscle (Table S3). Similarly, 85 and 99 proteins were upregulated by more than two-fold in fusion-negative and fusion-positive RMS, respectively (Tables S4 and S5). To identify high-confidence cell surface targets in RMS, we interrogated a transcriptomic dataset (GSE108022) that consists of 66 fusion-negative RMS tumors, 35 fusion-positive RMS tumors, and 5 normal muscle tissues to analyze the gene expressions of our target candidates [5]. By using a two-fold increase and a $p$-value of 0.05 as the cut-off, we found that $42.1 \%$ (24 out of 57 ) of the targets overexpressed in all RMS cell lines at the protein level were also increased at the transcriptional level (Figure 2A and Table S6). When the samples were sub-grouped based on their fusion status, $35.3 \%$ (30 out of 85 ) and $38.4 \%$ (38 out of 99) of the targets were upregulated in RMS compared to normal muscle at the RNA level (Tables S7 and S8).

One major barrier to the development of effective antibody-based therapies is the expression of tumor targets within normal tissue causing on-target, off-tumor toxicity [21]. To improve the safety and minimize the off-tumor toxicity, tumor-enriched cell surface proteins must have a limited expression in normal organs. To determine which RMS-enriched cell surface proteins may be suitable as targets for antibody-based therapies, we analyzed their expression in normal tissues using publicly available GTEx transcriptomic and proteomic datasets [19,22] (Figure 2B-D). We also included Mesothelin (MSLN), CEACAM5, and HER2 (ERBB2), three common targets for CAR-T therapy in solid tumors demonstrating an acceptable safety profile in humans $[23,24]$. Among the three selected CAR-T targets, ERBB2 was the most expressed in normal tissue at the RNA level, followed by CEACAM5 and MSLN (Figure 2B and Table S9). Many (80.3\%) (41/51) of the RMS-enriched cell surface proteins had lower normal gene expression than ERBB2. The proteomic data showed that ERBB2 was also the most expressed protein among the three CAR-T targets (Figure 2C and Table S10), and 49\% (25/51) of the RMS-enriched cell surface proteins had a lower relative protein expression compared to ERBB2. The least and most abundant proteins in normal tissue were EFNA5 and MARCKSL1, respectively. A correlation analysis of the protein and RNA relative expression in normal tissues showed that most RMS-associated surface antigen candidates have a lower RNA expression and similar protein expression than the three CAR-T targets (Figure 2D). 
(A)

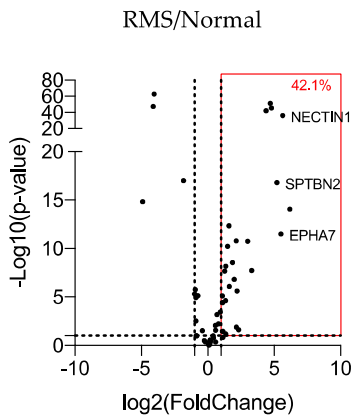

(B)

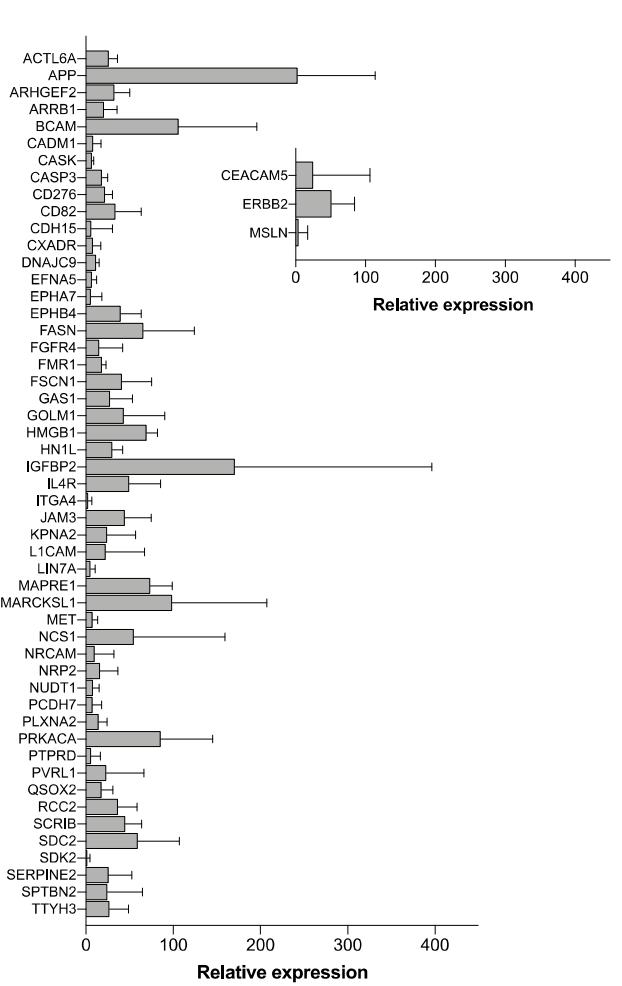

(D)

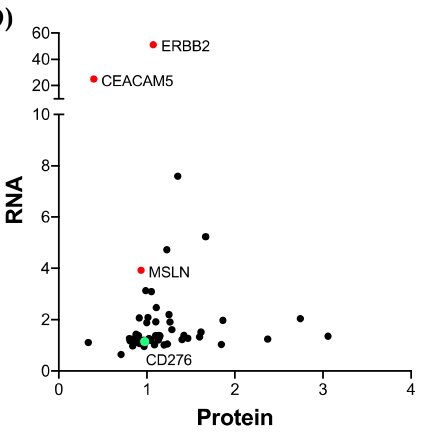

Fusion-Neg/Normal

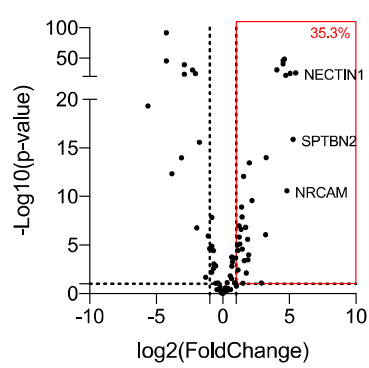

(C)

)

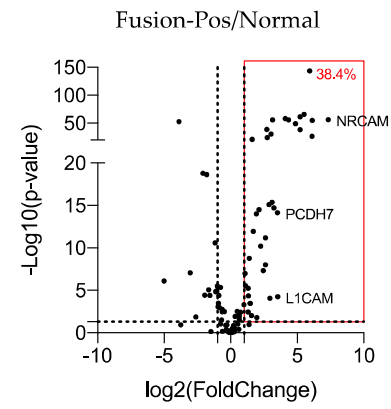

Protein

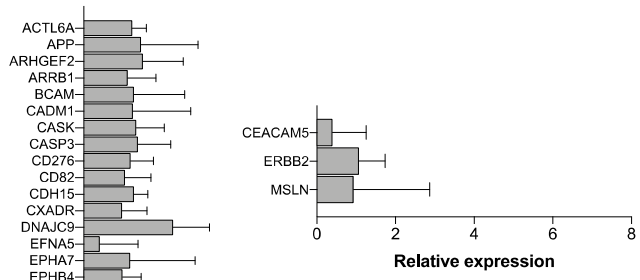

Figure 2. Validation of RMS-enriched cell-surface proteins by combined proteomic and transcriptomic analyses. (A) Volcano plot reporting $p$-values against fold changes for transcriptomic analysis of RMS tumors and normal muscle. The red box represents significantly up-regulated genes. Relative expression of (B) RNA and (C) protein of RMS-enriched cell-surface antigens in normal tissues including three CAR-T targets. (D) Correlation analysis between RNA and protein relative expression of RMS-enriched cell-surface antigens in normal tissues. Selected CAR-T targets and CD276 (B7-H3) are represented in red and green, respectively. 
Based on the RNA and protein expression on the tumor and normal tissues of cell surface antigens, we generated a composite rank by assigning equal weights to transcriptomic and proteomic ranks of overexpressed genes and proteins in RMS (Tables 1-3). For tumor expression, the gene and protein with the highest expression was assigned rank 1. For normal expression, the gene and protein with the lowest expression was assigned rank 1. A gene enrichment analysis revealed the enrichment of the proteins associated to neurogenesis, axon guidance, and cell adhesion (Figure S2).

Table 1. Composite ranking of RMS-enriched cell-surface proteins based on combined transcriptomic and proteomic analyses.

\begin{tabular}{|c|c|c|c|c|c|c|c|c|}
\hline Entry & Gene Names & Gene & $\begin{array}{l}\text { Proteomic } \\
\text { RMS }\end{array}$ & $\begin{array}{c}\text { Transcriptomic } \\
\text { RMS }\end{array}$ & $\begin{array}{l}\text { Proteomic } \\
\text { Normal }\end{array}$ & $\begin{array}{l}\text { Transcriptomic } \\
\text { Normal }\end{array}$ & $\begin{array}{l}\text { Composite } \\
\text { Sum }\end{array}$ & $\begin{array}{c}\text { Composite } \\
\text { Rank }\end{array}$ \\
\hline P55283 & $\mathrm{CDH} 4$ & $\mathrm{CDH} 4$ & 1 & 12 & 1 & 1 & 15 & 1 \\
\hline P52803 & $\begin{array}{l}\text { EFNA5 EPLG7 } \\
\text { LERK7 }\end{array}$ & EFNA5 & 1 & 9 & 2 & 4 & 16 & 2 \\
\hline Q92823 & $\begin{array}{c}\text { NRCAM } \\
\text { KIAA0343 }\end{array}$ & NRCAM & 4 & 1 & 13 & 6 & 24 & 3 \\
\hline O60245 & $\begin{array}{l}\text { PCDH7 } \\
\text { BHPCDH }\end{array}$ & PCDH7 & 9 & 8 & 5 & 5 & 27 & 4 \\
\hline Q15375 & $\begin{array}{c}\text { EPHA7 EHK3 } \\
\text { HEK11 }\end{array}$ & EPHA7 & 18 & 3 & 7 & 2 & 30 & 5 \\
\hline Q15223 & $\begin{array}{c}\text { NECTIN1 HVEC } \\
\text { PRR1 PVRL1 }\end{array}$ & NECTIN1 & 1 & 2 & 19 & 14 & 36 & 6 \\
\hline O14936 & CASK LIN2 & CASK & 5 & 21 & 12 & 3 & 41 & 7 \\
\hline O60462 & $\begin{array}{c}\text { NRP2 } \\
\text { VEGF165R2 }\end{array}$ & NRP2 & 7 & 22 & 3 & 9 & 41 & 7 \\
\hline P54826 & GAS1 & GAS1 & 8 & 14 & 6 & 17 & 45 & 9 \\
\hline Q06787 & FMR1 & FMR1 & 6 & 15 & 16 & 11 & 48 & 10 \\
\hline Q16658 & $\begin{array}{l}\text { FSCN1 FAN1 } \\
\text { HSN SNL }\end{array}$ & FSCN1 & 12 & 5 & 14 & 19 & 50 & 11 \\
\hline Q6ZRP7 & $\begin{array}{c}\text { QSOX2 } \\
\text { QSCN6L1 SOXN }\end{array}$ & QSOX2 & 20 & 11 & 10 & 10 & 51 & 12 \\
\hline Q9C0H2 & $\begin{array}{c}\text { TTYH3 } \\
\text { KIAA1691 }\end{array}$ & TTYH3 & 10 & 7 & 18 & 16 & 51 & 12 \\
\hline O15020 & $\begin{array}{c}\text { SPTBN2 } \\
\text { KIAA0302 SCA5 }\end{array}$ & SPTBN2 & 14 & 4 & 20 & 15 & 53 & 14 \\
\hline P32004 & $\begin{array}{l}\text { L1CAM CAML1 } \\
\text { MIC5 }\end{array}$ & L1CAM & 15 & 10 & 15 & 13 & 53 & 14 \\
\hline Q5ZPR3 & $\begin{array}{c}\text { CD276 B7H3 } \\
\text { PSEC0249 } \\
\text { UNQ309/PRO352 }\end{array}$ & CD276 & 23 & 13 & 8 & 12 & 56 & 16 \\
\hline O75051 & $\begin{array}{c}\text { PLXNA2 } \\
\text { KIAA0463 OCT } \\
\text { PLXN2 } \\
\text { UNQ209/PRO235 }\end{array}$ & PLXNA2 & 24 & 16 & 9 & 8 & 57 & 17 \\
\hline P09429 & HMGB1 HMG1 & HMGB1 & 11 & 24 & 4 & 22 & 61 & 18 \\
\hline Q8WXX5 & DNAJC9 & DNAJC9 & 17 & 18 & 22 & 7 & 64 & 19 \\
\hline P49006 & $\begin{array}{l}\text { MARCKSL1 } \\
\text { MLP MRP }\end{array}$ & MARCKSL1 & 16 & 6 & 24 & 24 & 70 & 20 \\
\hline Q9H910 & $\begin{array}{l}\text { JPT2 C16orf34 } \\
\text { HN1L L11 }\end{array}$ & HN1L & 13 & 19 & 23 & 18 & 73 & 21 \\
\hline P34741 & SDC2 HSPG1 & SDC2 & 22 & 20 & 11 & 21 & 74 & 22 \\
\hline Q15691 & MAPRE1 & MAPRE1 & 19 & 17 & 21 & 23 & 80 & 23 \\
\hline Q14160 & $\begin{array}{c}\text { SCRIB CRIB1 } \\
\text { KIAA0147 LAP4 } \\
\text { SCRB1 VARTUL }\end{array}$ & SCRIB & 21 & 23 & 17 & 20 & 81 & 24 \\
\hline
\end{tabular}


Table 2. Composite ranking of fusion-negative RMS-enriched cell-surface proteins based on combined transcriptomic and proteomic analyses.

\begin{tabular}{|c|c|c|c|c|c|c|c|c|}
\hline Entry & Gene Names & Gene & $\begin{array}{l}\text { Surfaceomic } \\
\text { RMS }\end{array}$ & $\begin{array}{c}\text { Transcriptomic } \\
\text { RMS }\end{array}$ & $\begin{array}{l}\text { Proteomic } \\
\text { Normal }\end{array}$ & $\begin{array}{c}\text { Transcriptomic } \\
\text { Normal }\end{array}$ & $\begin{array}{l}\text { Composite } \\
\text { Sum }\end{array}$ & $\begin{array}{c}\text { Composite } \\
\text { Rank }\end{array}$ \\
\hline P52803 & $\begin{array}{l}\text { EFNA5 EPLG7 } \\
\text { LERK7 }\end{array}$ & EFNA5 & 1 & 10 & 1 & 3 & 15 & 1 \\
\hline Q92823 & $\begin{array}{l}\text { NRCAM } \\
\text { KIAA0343 }\end{array}$ & NRCAM & 8 & 4 & 12 & 7 & 31 & 2 \\
\hline Q15223 & $\begin{array}{l}\text { NECTIN1 HVEC } \\
\text { PRR1 PVRL1 }\end{array}$ & NECTIN1 & 1 & 1 & 19 & 13 & 34 & 3 \\
\hline O60245 & $\begin{array}{c}\text { PCDH7 } \\
\text { BHPCDH }\end{array}$ & PCDH7 & 15 & 11 & 5 & 4 & 35 & 4 \\
\hline Q9BY67 & $\begin{array}{l}\text { CADM1 IGSF4 } \\
\text { IGSF4A NECL2 } \\
\text { SYNCAM TSLC1 }\end{array}$ & CADM1 & 1 & 19 & 9 & 6 & 35 & 4 \\
\hline P27701 & $\begin{array}{l}\text { CD82 KAI1 } \\
\text { SAR2 ST6 } \\
\text { TSPAN27 }\end{array}$ & CD82 & 1 & 14 & 2 & 20 & 37 & 6 \\
\hline O14910 & $\begin{array}{l}\text { LIN7A MALS1 } \\
\text { VELI1 }\end{array}$ & LIN7A & 1 & 17 & 22 & 1 & 41 & 7 \\
\hline P22455 & FGFR4 JTK2 TKF & FGFR4 & 13 & 3 & 20 & 9 & 45 & 8 \\
\hline O14936 & CASK LIN2 & CASK & 7 & 26 & 11 & 2 & 46 & 9 \\
\hline Q8NBJ4 & $\begin{array}{c}\text { GOLM1 } \\
\text { C9orf155 } \\
\text { GOLPH2 } \\
\text { PSEC0242 }\end{array}$ & GOLM1 & 10 & 13 & 3 & 22 & 48 & 10 \\
\hline P54826 & GAS1 & GAS1 & 12 & 16 & 6 & 18 & 52 & 11 \\
\hline Q06787 & FMR1 & FMR1 & 9 & 18 & 15 & 12 & 54 & 12 \\
\hline Q9C0H2 & $\begin{array}{c}\text { TTYH3 } \\
\text { KIAA1691 }\end{array}$ & ТТҮН3 & 16 & 7 & 18 & 17 & 58 & 13 \\
\hline O15020 & $\begin{array}{c}\text { SPTBN2 } \\
\text { KIAA0302 SCA5 }\end{array}$ & SPTBN2 & 18 & 2 & 25 & 14 & 59 & 14 \\
\hline P18065 & IGFBP2 BP2 IBP2 & IGFBP2 & 1 & 5 & 24 & 29 & 59 & 14 \\
\hline P36639 & NUDT1 MTH1 & NUDT1 & 25 & 12 & 23 & 5 & 65 & 16 \\
\hline Q16658 & $\begin{array}{l}\text { FSCN1 FAN1 } \\
\text { HSN SNL }\end{array}$ & FSCN1 & 24 & 8 & 14 & 21 & 67 & 17 \\
\hline Q6ZRP7 & $\begin{array}{c}\text { QSOX2 } \\
\text { QSCN6L1 SOXN }\end{array}$ & QSOX2 & 26 & 24 & 7 & 10 & 67 & 17 \\
\hline P42574 & CASP3 СРP32 & CASP3 & 14 & 30 & 13 & 11 & 68 & 19 \\
\hline O96019 & $\begin{array}{l}\text { ACTL6A BAF53 } \\
\text { BAF53A INO80K }\end{array}$ & ACTL6A & 30 & 23 & 8 & 16 & 77 & 20 \\
\hline Р07093 & $\begin{array}{c}\text { SERPINE2 PI7 } \\
\text { PN1 }\end{array}$ & SERPINE2 & 27 & 15 & 21 & 15 & 78 & 21 \\
\hline P09429 & HMGB1 HMG1 & HMGB1 & 20 & 28 & 4 & 26 & 78 & 21 \\
\hline P62166 & $\begin{array}{l}\text { NCS1 FLUP } \\
\text { FREQ }\end{array}$ & NCS1 & 17 & 9 & 28 & 24 & 78 & 21 \\
\hline Q8WXX5 & DNAJC9 & DNAJC9 & 21 & 22 & 27 & 8 & 78 & 21 \\
\hline P34741 & SDC2 HSPG1 & SDC2 & 28 & 21 & 10 & 25 & 84 & 25 \\
\hline Q14160 & $\begin{array}{l}\text { SCRIB CRIB1 } \\
\text { KIAA0147 LAP4 } \\
\text { SCRB1 VARTUL }\end{array}$ & SCRIB & 19 & 25 & 17 & 23 & 84 & 26 \\
\hline P05067 & APP A4 AD1 & $\mathrm{APP}$ & 11 & 29 & 16 & 30 & 86 & 27 \\
\hline P49006 & $\begin{array}{l}\text { MARCKSL1 } \\
\text { MLP MRP }\end{array}$ & MARCKSL1 & 23 & 6 & 30 & 28 & 87 & 28 \\
\hline Q9H910 & $\begin{array}{c}\text { JPT2 C16orf34 } \\
\text { HN1L L11 }\end{array}$ & HN1L & 22 & 27 & 29 & 19 & 97 & 28 \\
\hline Q15691 & MAPRE1 & MAPRE1 & 29 & 20 & 26 & 27 & 102 & 30 \\
\hline
\end{tabular}


Table 3. Composite ranking of fusion-positive RMS-enriched cell-surface proteins based on combined transcriptomic and proteomic analyses.

\begin{tabular}{|c|c|c|c|c|c|c|c|c|}
\hline Entry & Gene Names & Gene & $\begin{array}{l}\text { Surfaceomic } \\
\text { RMS }\end{array}$ & $\begin{array}{l}\text { Transcriptomic } \\
\text { RMS }\end{array}$ & $\begin{array}{c}\text { Proteomic } \\
\text { Normal }\end{array}$ & $\begin{array}{l}\text { Transcriptomic } \\
\text { Normal }\end{array}$ & $\begin{array}{l}\text { Composite } \\
\text { Sum }\end{array}$ & $\begin{array}{c}\text { Composite } \\
\text { Rank }\end{array}$ \\
\hline P55283 & $\mathrm{CDH} 4$ & $\mathrm{CDH} 4$ & 1 & 17 & 1 & 1 & 20 & 1 \\
\hline Q58EX2 & SDK2 KIAA1514 & SDK2 & 1 & 6 & 11 & 4 & 22 & 2 \\
\hline Q96KG7 & MEGF10 KIAA1780 & MEGF10 & 15 & 9 & 1 & 1 & 26 & 3 \\
\hline O00762 & UBE2C UBCH10 & UBE2C & 23 & 2 & 1 & 1 & 27 & 4 \\
\hline P52803 & EFNA5 EPLG7 LERK7 & EFNA5 & 1 & 23 & 4 & 10 & 38 & 5 \\
\hline P49407 & ARRB1 ARR1 & ARRB1 & 1 & 13 & 13 & 18 & 45 & 6 \\
\hline P78310 & CXADR CAR & CXADR & 1 & 26 & 6 & 13 & 46 & 7 \\
\hline Q15375 & EPHA7 EHK3 HEK11 & EPHA7 & 22 & 3 & 17 & 6 & 48 & 8 \\
\hline Q92823 & NRCAM KIAA0343 & NRCAM & 8 & 1 & 26 & 14 & 49 & 9 \\
\hline O60245 & PCDH7 BHPCDH & PCDH7 & 13 & 12 & 15 & 11 & 51 & 10 \\
\hline P24394 & IL4R IL4RA 582J2.1 & IL4R & 1 & 21 & 5 & 31 & 58 & 11 \\
\hline Q15223 & $\begin{array}{l}\text { NECTIN1 HVEC PRR1 } \\
\text { PVRL1 }\end{array}$ & NECTIN1 & 1 & 4 & 35 & 21 & 61 & 12 \\
\hline P23468 & PTPRD & PTPRD & 18 & 5 & 34 & 7 & 64 & 13 \\
\hline O60462 & NRP2 VEGF165R2 & NRP2 & 11 & 30 & 9 & 15 & 65 & 14 \\
\hline P08581 & MET & MET & 16 & 36 & 8 & 12 & 72 & 15 \\
\hline $\mathrm{P} 13612$ & ITGA4 CD49D & ITGA4 & 38 & 22 & 10 & 5 & 75 & 16 \\
\hline O14936 & CASK LIN2 & CASK & 9 & 33 & 25 & 9 & 76 & 17 \\
\hline P32004 & L1CAM CAML1 MIC5 & L1CAM & 17 & 11 & 29 & 20 & 77 & 18 \\
\hline P52292 & KPNA2 RCH1 SRP1 & KPNA2 & 14 & 16 & 27 & 22 & 79 & 19 \\
\hline Q9P258 & RCC2 KIAA1470 TD60 & RCC2 & 26 & 14 & 12 & 27 & 79 & 19 \\
\hline Q06787 & FMR1 & FMR1 & 10 & 25 & 30 & 17 & 82 & 21 \\
\hline P54826 & GAS1 & GAS1 & 21 & 24 & 16 & 24 & 85 & 22 \\
\hline Q9C0H2 & TTYH3 KIAA1691 & TTYH3 & 19 & 10 & 33 & 23 & 85 & 22 \\
\hline Q6ZRP7 & $\begin{array}{l}\text { QSOX2 QSCN6L1 } \\
\text { SOXN }\end{array}$ & QSOX2 & 36 & 15 & 19 & 16 & 86 & 24 \\
\hline P55291 & CDH15 CDH14 CDH3 & CDH15 & 37 & 19 & 23 & 8 & 87 & 25 \\
\hline Q92974 & $\begin{array}{l}\text { ARHGEF2 KIAA0651 } \\
\text { LFP40 }\end{array}$ & ARHGEF2 & 12 & 20 & 32 & 26 & 90 & 26 \\
\hline Q16658 & $\begin{array}{l}\text { FSCN1 FAN1 HSN } \\
\text { SNL }\end{array}$ & FSCN1 & 28 & 7 & 28 & 29 & 92 & 27 \\
\hline Q5ZPR3 & $\begin{array}{l}\text { CD276 B7H3 PSEC0249 } \\
\text { UNQ309/PRO352 }\end{array}$ & CD276 & 29 & 27 & 18 & 19 & 93 & 28 \\
\hline P54760 & $\begin{array}{l}\text { EPHB4 HTK MYK1 } \\
\text { TYRO11 }\end{array}$ & EPHB4 & 31 & 32 & 7 & 28 & 98 & 29 \\
\hline Q9BX67 & $\begin{array}{c}\text { JAM3 } \\
\text { UNQ859/PRO1868 }\end{array}$ & JAM3 & 33 & 18 & 21 & 30 & 102 & 30 \\
\hline P09429 & HMGB1 HMG1 & HMGB1 & 20 & 38 & 14 & 34 & 106 & 31 \\
\hline P49006 & MARCKSL1 MLP MRP & MARCKSL1 & 34 & 8 & 38 & 37 & 117 & 32 \\
\hline P50895 & BCAM LU MSK19 & BCAM & 27 & 31 & 22 & 38 & 118 & 33 \\
\hline P49327 & FASN FAS & FASN & 32 & 34 & 20 & 33 & 119 & 34 \\
\hline Q9H910 & $\begin{array}{l}\text { JPT2 C16orf34 HN1L } \\
\text { L11 }\end{array}$ & HN1L & 30 & 29 & 37 & 25 & 121 & 35 \\
\hline Q15691 & MAPRE1 & MAPRE1 & 25 & 28 & 36 & 35 & 124 & 36 \\
\hline P17612 & PRKACA PKACA & PKACA & 24 & 35 & 31 & 36 & 126 & 37 \\
\hline P34741 & SDC2 HSPG1 & SDC2 & 35 & 37 & 24 & 32 & 128 & 38 \\
\hline
\end{tabular}


Using combined proteomic and transcriptomic analyses of RMS tumors and normal tissue, we identified several cell surface proteins enriched in RMS and with limited expression in normal tissue, suggesting they are potential RMS target candidates for antibody-based therapies.

\subsection{The Immune Checkpoint Molecule B7-H3 Is Upregulated in Both Fusion-Negative and Fusion-Positive RMS}

Among the cell surface proteins that were upregulated at the RNA and protein levels in RMS compared to the normal muscle and limited expression in normal tissue, we identified the immune checkpoint molecule B7-H3 (Tables 1-3 and Figure 2D). B7-H3 (CD276) is a member of the B7 family that consists of 10 immune checkpoint molecules, including the well-known immunotherapeutic target B7-H1 (PD-L1) [25]. B7-H3 represents a promising target for the treatment of RMS, because it not only appears as one of the most upregulated cell surface antigens in tumors but, also, its immunoregulatory function may provide novel insights on the mechanisms associated with tumor immune evasion for the development of new immune checkpoint inhibitors.

The Gene expression profiles of the B7 molecules showed B7-H3 as the most expressed B7 molecule in RMS, and the tumor expression was significantly higher in $100 \%$ of both fusion-negative RMS (9.45-fold) and fusion-positive RMS (7.03-fold) (Figure 3A). The B7-H6 gene expression was significantly increased in fusion-negative RMS. B7-H4 was upregulated in both RMS subtypes but at a greater extent in fusion-positive RMS $(p=0.06)$. Strikingly, both PD-L1 (B7-H1) and PD-L2 (B7-DC) were significantly downregulated in RMS compared to normal muscle. The cell surface protein expression of the B7 molecules was also assessed by flow cytometry in normal skeletal muscle cells, fusion-negative (RD), and fusion-positive RMS (RH30) (Figure 3B). Similar findings were obtained with B7-H3 being the most expressed B7 member, with a 3.42-fold increase in RMS cells. In contrast, PD-L1 and PD-L2 were downregulated in RMS, which corroborates with transcriptomic data. While B7-H4 and B7-H7 were not detected on the surfaces of normal and cancer cells, B7-H6 were weakly expressed in normal muscle and downregulated in RMS cell lines. In the proteomic data, the B7-H6 protein was expressed at low levels in three RMS cell lines (Table S1). A Western blot of the cell lines showed a similar increase of the total B7-H3 proteins in the RMS cell lines compared to the normal muscle (Figure 3C). We analyzed the tissue specificity score of B7-H3 in normal tissue as described previously [19]. The tissue specificity (TS) score defines the enrichment of B7H3 across normal tissues. A score superior of 2.5 means a protein is tissue-enriched, and a score superior of 4 defines a tissuespecific protein. An expression analysis in normal tissue showed a positive correlation between the RNA and protein expression of B7-H3 (Spearman correlation $\rho=0.84$ ), and no tissue specificity was observed (Figure 3D).

To validate the differential expression of B7-H3 in normal tissue and RMS tumors, we first evaluated the sensitivity and specificity of four commercial antibodies using tumor xenografts of RMS wild-type and knockout cells for B7-H3 (Figure S3). While all antibodies showed positive signals and well-defined membrane staining in RH30 wild-type cells, no unspecific signal was detected with the AF1027 and EPNCIR122 antibodies (Figure S3C). The AF1027 clone was selected for tissue staining.

We performed staining on a normal human tissue microarray and RMS tumor sections. The tissue microarray consisted of three specimens for 32 normal tissues. No positive detection of B7-H3 was observed in normal human tissues (Figure 4A). We also analyzed B7-H3 tissue expression in a cohort of 132 RMS specimens ( $N=97$ patients) obtained from our institutional tissue registry (Table S11). B7-H3 expression was detected in 122/132 specimens (91.5\%) with only 10 samples $(8.5 \%)$ with negative expression. The RMS tumor specimens showed various levels of B7-H3 expression and intratumoral heterogeneity (Figure 4B). The staining of RMS tumor cells with Myogenin and MyoD1 revealed that B7-H3 is expressed by tumor cells and not detected in the stroma or tumor-infiltrating immune cells. The quantification of B7-H3 expression did not show any statistical differences between FN-RMS and FP-RMS. The median H-score was 60 and 80 for FN-RMS and FP-RMS, respectively. 
Furthermore, no association was observed between the B7-H3 expression and histological or molecular subtype (Table S11). Altogether, these findings showed that B7-H3 is not expressed by normal tissue at both the RNA and protein levels, while it is strongly expressed in most RMS tumors, regardless of the molecular subtype.

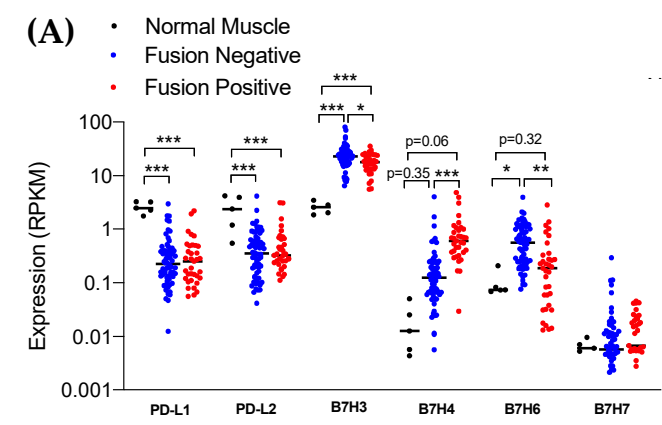

(C)

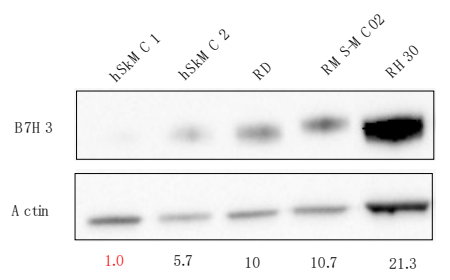

(B)

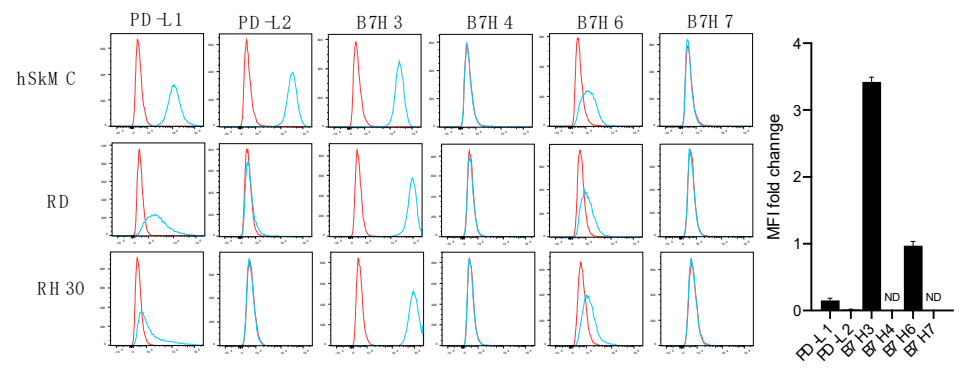

(D)
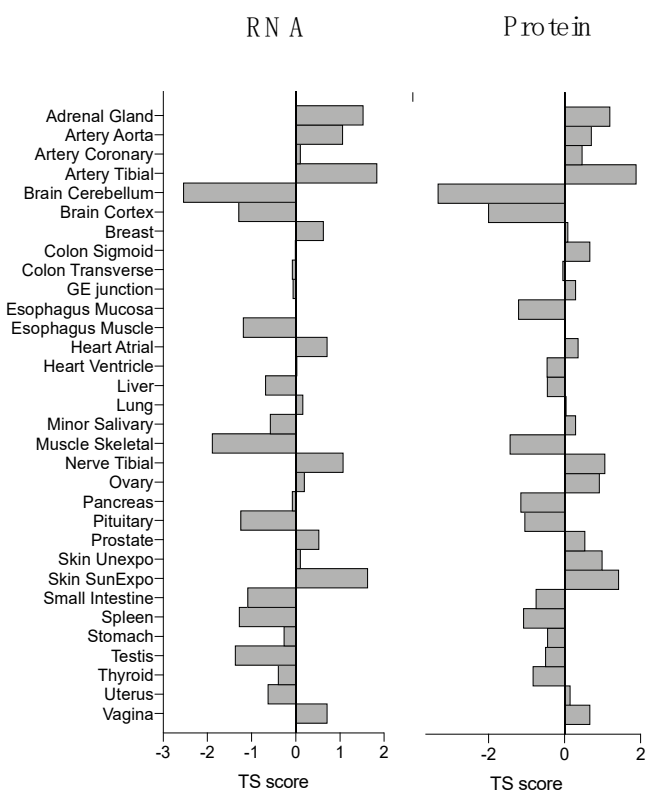

Figure 3. Expression of the immune checkpoint molecule B7-H3 in RMS and normal tissue. (A) Normalized expression (RPKM) of B7 molecules from RNA sequencing of normal muscle $(\mathrm{N}=5)$, fusion negative $(\mathrm{N}=66)$, and fusion positive $(\mathrm{N}=35)$ RMS samples. Each data point represents an individual sample. The median is noted by a horizontal bar and significance denoted by asterisks $\left({ }^{* * *} p<0.001 ;{ }^{* *} p<0.01{ }^{*} p<0.05\right.$; n.s., not significant, Student's t-test). (B) Histograms of flow cytometric analysis of B7 molecule expression in RMS and normal muscle cell lines. Bar graph shows mean fluorescence intensity (MFI) fold change in RMS cell lines compared to normal muscle. ND indicates "not detectable" expression (C) Western blot of B7H3 expression in 5 different cell lines. Band intensity for B7-H3 normalized on actin is indicated for each cell line. (D) Tissue Specific (TS) score of protein and RNA expression of B7H3 in each normal tissue (obtained from Jiang et al. [15]).

\subsection{Tumor B7-H3 Overexpression Is Associated with Low Infiltration of CD8 ${ }^{+}-T$ Cells in RMS Tumors and Impaired Antitumor Immune Response}

B7-H3 has shown paradoxical roles in tumor immunity [26]. Described originally as a costimulatory molecule, B7-H3 has also been linked to inhibition of the antitumor immune response and immune evasion $[27,28]$. The immunomodulatory role of B7-H3 and its relationship with tumor-infiltrating immune cells in RMS remains unknown. To address this unmet need, we investigated the immune landscape of fusion-positive and fusionnegative RMS by a deconvolution analysis of bulk RNA-seq data. We employed QuantiSeq, a computational pipeline, for the characterization and quantification of 10 tumor-infiltrating 
immune cell subsets [20]. An additional population called "Other" includes nonimmune cells such as malignant cells and fibroblasts. The relative abundance of different immune cell subsets was determined for normal muscle, fusion-negative, and fusion-positive RMS (Figure 5A,B). Higher proportions of monocytes, B-cells, macrophages M2, NK cells, CD4-T cells, CD8-T cells, and regulatory $\mathrm{T}$ cells were observed in both fusion-negative and fusionpositive RMS compared to normal muscle. In contrast, a higher content in neutrophils was found in normal muscle. Monocytes, neutrophils, and CD4-T cells represented $\sim 70 \%$ of the immune cell content in RMS tumors, and no difference was observed between fusion-negative and fusion-positive RMS.

(A)

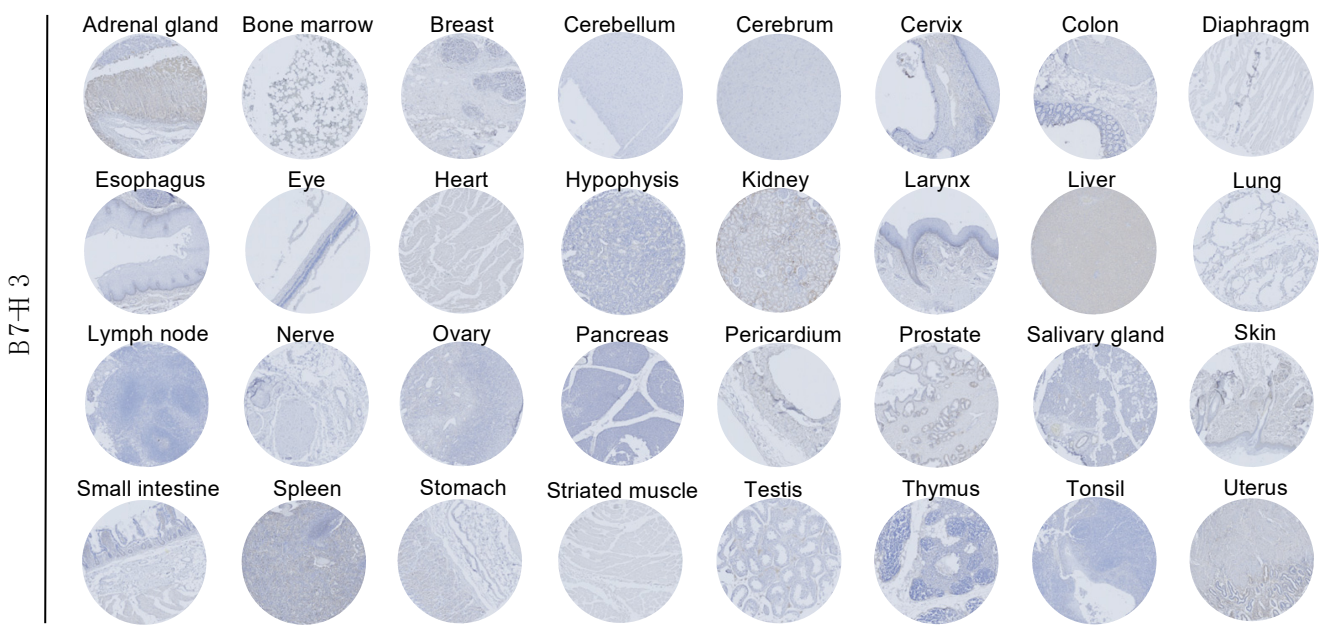

(B)
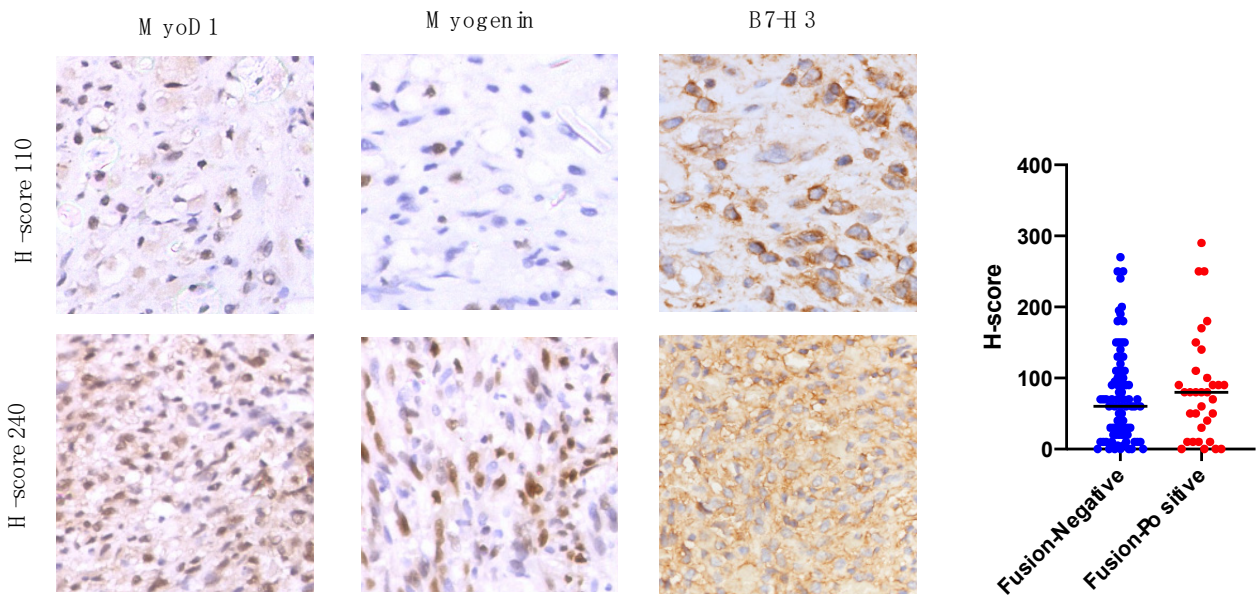

Figure 4. B7-H3 tissue expression in normal organs and RMS tumor specimens. (A) Immunohistochemical staining of B7H3 in a microarray of 32 normal tissues. Representative picture of triplicates for each tissue. (B) Representative picture of immunohistochemistry for MyoD1, Myogenin and B7H3 in RMS tumors. Scatter plot shows quantification of B7-H3 expression using H-scoring system in fusion-negative and fusion-positive RMS tumors $(\mathrm{N}=132)$. 


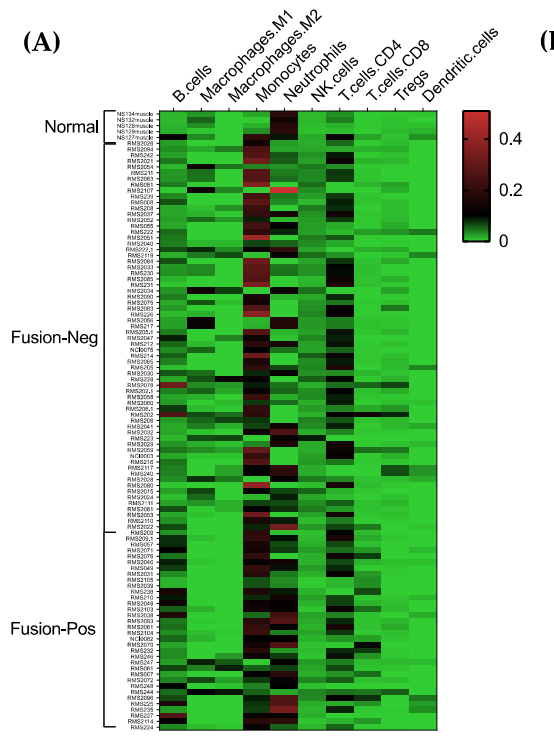

(B)

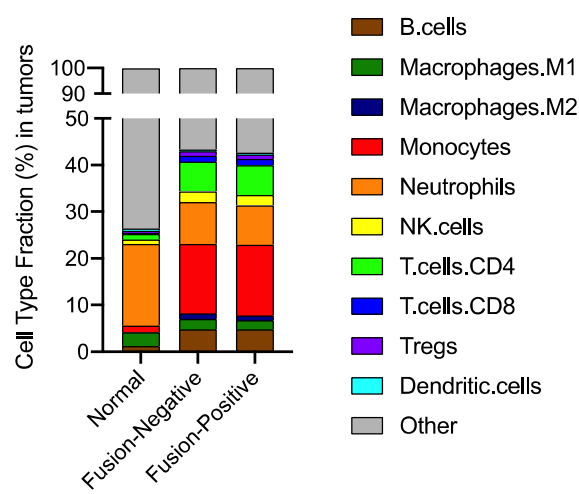

(C)

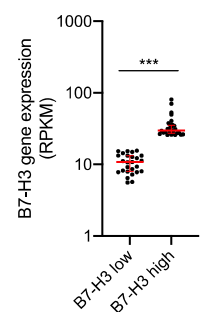

(E)

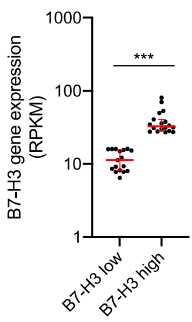

(G)

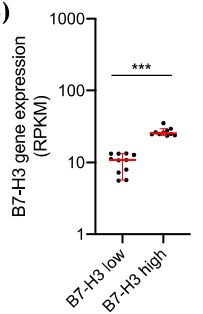

(D)
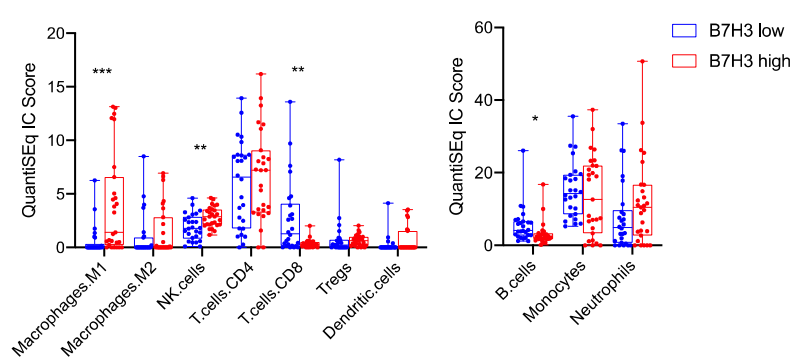

(F)
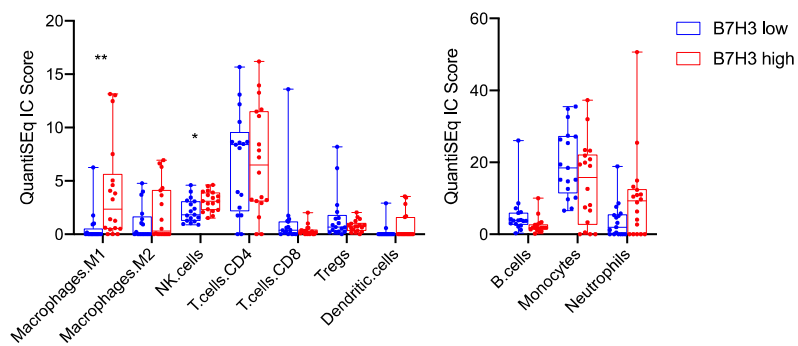

(H)
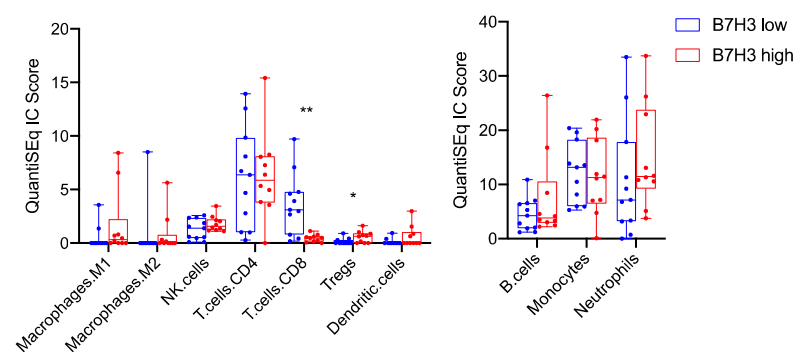

Figure 5. Relationship of B7-H3 expression and tumor-infiltrating immune cells in RMS. (A) Heatmap of immune cell abundance estimated by QuantiSeq analysis in normal muscle, fusion-negative and fusion-positive RMS. (B) Mean percentages of different immune cell subsets in normal muscle, fusion-negative and fusion-positive RMS. (C,E,G) B7-H3 RNA expression in quartile subgroups (25\% highest, 25\% lowest) in RMS tumors (C), FN-RMS (E) and FP-RMS (G) used for immune cell abundance analysis. (D,F,H) Bar graphs showing immune cell abundance between B7-H3-low and B7-H3-rich RMS tumors (D), FN-RMS only (F) and FP-RMS only (H). Significance is denoted by asterisks $\left({ }^{* * *} p<0.001 ;{ }^{* *} p<0.01 ;{ }^{*} p<0.05\right.$; Student's $t$-test).

To determine the relationship between $\mathrm{B} 7-\mathrm{H} 3$ expression and tumor-infiltrating immune cells, we measured the immune cell abundance in B7-H3-low and B7-H3-high tumors using quartile subgroups ( $25 \%$ highest and $25 \%$ lowest). Regardless of the fusion status, 
B7-H3-high tumors were enriched in M1 macrophages and NK cells and depleted in CD8-T cells and B cells (Figure 5C,D). In fusion-negative RMS only, M1 macrophages and NK cells were significantly higher in B7-H3-rich tumors. Despite a trend toward a decrease of CD8-T-cell abundance in B7-H3-rich tumors, it was not statistically significant (Figure 5E,F). In fusion-positive RMS, only the infiltration of regulatory $\mathrm{T}$ cells and CD8-T cells were significantly affected by B7-H3 expression, where B7-H3-rich tumors have a higher infiltration of Tregs and depletion of CD8-T cells (Figure 5G,H). Correlation matrices were used to determine the degree of relationships between B7-H3 expression and the abundance of different immune cell subsets (Table S12). In fusion-negative RMS, a significant positive correlation was found between $\mathrm{B} 7-\mathrm{H} 3$ and $\mathrm{M} 1$ macrophages and neutrophils. A moderate negative correlation was also observed between B7-H3 and M2 macrophages and monocytes. Only CD8-T cells and B7-H3 showed a significant negative correlation in both fusion-negative and fusion-positive RMS.

To confirm a potential association between B7-H3 and CD8-T cells, we performed a T-cell cytotoxicity assay by coculturing activated PBMC isolated from 10 healthy donors with RH30 wild-type or knockout cells for B7-H3 and monitored the tumor cell survival over time. No significant difference was observed in B7-H3 knockout RH30 cells compared to the wild type (Figure 6A). For eight out of 10 normal donors, the loss of B7-H3 was associated with an increase in tumor cell killing (Figure $6 \mathrm{~B}, \mathrm{C}$ ). A decrease of $34 \%$ and $45 \%$ in tumor cell survival was observed with B7-H3 knockout tumor cells at a ratio of 1:10 and 1:20 RH30:PBMC, respectively.

(A)

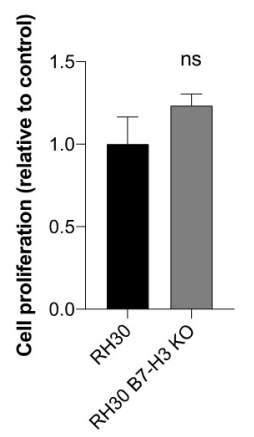

(B)

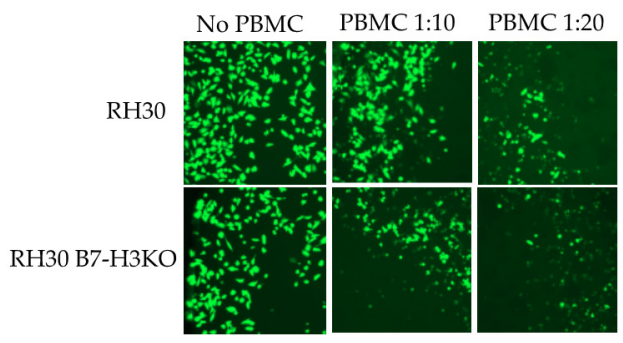

(C)

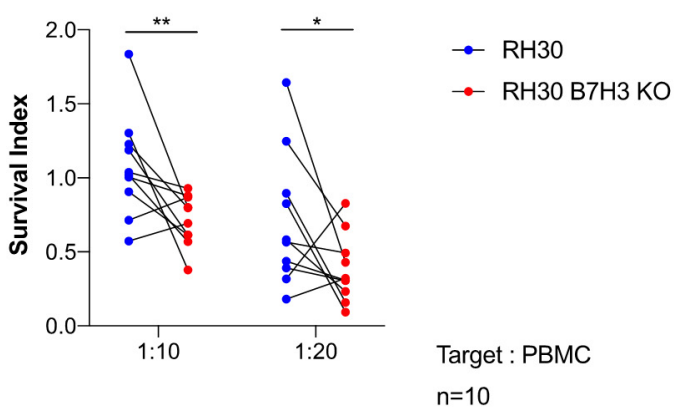

Figure 6. Loss of B7-H3 expression in RMS tumor cells is associated with higher T-cell cytotoxicity. (A) Histogram showing relative proliferation of B7-H3 knockout RH30 cells compared to wild-type cells. (B) Representative pictures of calcein-labeled wild-type and B7-H3 knockout RH30 cells after co-incubation with activated PBMCs for 4 hours. (C) Survival index of wild-type and B7-H3 knockout RH30 cells co-cultured with activated PBMC ( $N=10$ normal donors) at a ratio target: PBMC of 1:10 or 1:20. ${ }^{* *} p<0.01 ; * p<0.05$, Paired $t$-test).

Altogether, these data show that B7-H3 tumor expression is associated with the distinct immune composition of RMS tumors rich in M1 macrophages, M2 macrophages, and neutrophils and depleted in T cells. In addition, B7-H3 expression in RMS is associated with the inhibition of T-cell cytotoxic functions. 


\section{Discussion}

In this study, we conducted the first comprehensive characterization of the cell surface proteome (surfaceome) of RMS tumors using cell surface capture and mass spectrometrybased proteomics to identify new therapeutic targets. As a result of the technological advances and reduced costs, conventional proteomics has become an attractive tool for target discovery and therapeutic development. However, it suffers from low sensitivity for cell surface proteins, which are significantly less abundant and soluble than cytosolic proteins [29]. Although surfaceomic approaches have been shown to circumvent this challenge and enhance target discovery, it has not been widely adopted, as several challenges have limited its use [30-32]. It requires a large number of starting living cells that may complicate the use of primary cells that have a limited number of passages in $2 \mathrm{D}$ cultures. Alongside the established RMS cell lines, we successfully analyzed the surfaceome of one primary cell line cultured from a patient-derived RMS (RMS-MC02), while three other primary cell lines did not reach the number of cells desired. Although a limited number of cell lines have been used for surfaceomic profiling, we included a bioinformatic analysis of publicly available transcriptomic and proteomic datasets of RMS specimens and normal tissues to reveal high-confidence therapeutic targets for the treatment of RMS. We benefited from the RNA sequencing and proteomic profiling of normal organs to determine the basal expression of RMS-enriched surface proteins in human organs. The success of antibody-based and cell-based therapies relies not only on the recognition of an antigen highly expressed on tumor cells but, also, on the minimal on-target off-tumor toxicities caused by the expression of the same antigen on normal cells [23]. By analyzing the gene and protein expressions in RMS and normal tissue, we uncovered a repertoire of surface antigens targetable with targeted therapies and immunotherapies.

Among the cell surface proteins enriched in FN-RMS and FP-RMS, we rediscovered several molecules previously reported by other groups [5]. For instance, we identified the FGFR4 receptor overexpressed in FN-RMS, which is in line with the prior observations of FGFR4 mutation and amplification in this RMS subtype [5]. Several well-known PAX3/7FOXO1 target genes were also reported among the top cell surface proteins in FP-RMS, including MET, IL4R, FMR1, and NRCAM [33]. Interestingly, FMR and NRCAM were also upregulated in FN-RMS, suggesting similarities in the protein repertoires regardless of the fusion status. An outstanding work from Shern et al. showed that fusion-negative and fusion-positive RMS display common altered pathways, including the RAS/PIK3CA axis [5]. The hierarchical clustering of RMS surfaceome signatures does not separate fusionnegative and fusion-positive RMS, which corroborates with the previous findings. Gene overexpression either through PAX3/7-FOXO1 activity or mutation-associated amplification in FN-RMS may explain the high similarities in the cell surface protein repertoire of both molecular subtypes. This is of utmost interest, as it suggests that therapeutic strategies can be designed to target proteins commonly enriched in both RMS subtypes.

Our surfaceomic analysis also revealed new targetable RMS-enriched cell surface proteins. Among the commonly overexpressed proteins in both RMS subtypes, we identified the cell adhesion molecule CDH4 and ephrin receptors EFNA5 and EPHA7. CDH4 (R-Cadherin) has been previously found amplified in $43.6 \%$ of osteosarcomas, and its overexpression was associated with metastasis and a poor prognosis [34]. Similarly, CDH4 is an important driver of metastasis in glioblastoma [35]. In skeletal muscle, CDH4 has been reported to block myogenesis process and induce myoblast transformation, suggesting a potential oncogenic role in rhabdomyosarcoma [36]. Ephrin A5 and A7 are tyrosine kinase receptors that both bind the ephrin A5 ligand [37]. Ephrin receptors play a large role in embryonic and neural development [38]. In disease, Ephrin receptors and ligands can mediate the metastatic potential of cancer cells [39]. Little is known about the exact roles of Ephrin A5 and A7 in cancer progression. A few studies point towards a paradoxical role with pro- and antimetastatic functions, suggesting disease-specific activity [40-42]. The identification of new RMS-enriched tumor antigens, such as CDH4, Ephrin A5, and A7, support the clinical relevance of using surfaceomics for target discovery and drug 
development. Moreover, it provides novel biological insights into RMS pathology. Further studies are warranted to elucidate the roles of CDH4 and Ephrin A5/A7 in RMS, paving the way for the development of new treatments preventing disease recurrence and metastasis.

Another interesting target identified in our study is the immune checkpoint molecule B7-H3. B7-H3 is a member of the B7 family that contains ten members, including the wellknown immune checkpoint PD-L1, the target of FDA-approved immunotherapies [25]. We identified B7-H3 as the major B7 immune molecule expressed on the surface of RMS cells. In our cohort of RMS specimens, only $8.55 \%$ of samples tested were negative for $\mathrm{B} 7-\mathrm{H} 3$, and no difference was observed between FN-RMS or FP-RMS. Interestingly, PD-L1 was poorly expressed in RMS cells, and it was significantly lower than in normal muscle. This is in accordance with the previous reports of a minimal or negative expression of PD-L1 in rhabdomyosarcoma [43,44]. B7-H3 has a multifaceted role in cancer, including immunological and nonimmunological functions [45,46]. Herein, we provided the first biological insights of the B7-H3 role in RMS. We analyzed the impact of B7-H3 expression in the immune composition of RMS tumors by deconvolution of the RNA-seq data. Interestingly, we found that RMS tumors rich in B7-H3 are depleted in CD8-T cells. Furthermore, B7-H3 knockout in RMS cells was associated with greater T-cell-mediated cytotoxicity. Altogether, this suggests that B7-H3 acts as an immune-inhibitory molecule in RMS. The underlying molecular and cellular mechanisms of B7-H3-mediated antitumor immunity remain to be elucidated, and unlike PD-L1, the B7-H3 receptor on immune cells has not been identified yet. Interestingly, we also found a positive correlation between B7-H3 expression and an abundance of neutrophils and M1 macrophages in FN-RMS. In colorectal cancer and hepatocellular carcinoma, B7-H3 tumor expression was associated with a higher infiltration of CD68 ${ }^{+}$ macrophages and the polarization of M1 to M2 macrophages [47,48]. While it was not statistically significant, we also observed higher infiltration of M2 macrophages in B7-H3rich FN-tumors. This suggests that B7-H3 may drive the polarization of M1 macrophages towards the tumor-promoting M2 phenotype. Finally, the overexpression of B7-H3 in tumors compared to normal muscle was associated with a higher monocyte infiltration. Tumor-associated monocytes can differentiate into myeloid suppressor-derived cells, which are an important contributor of the immunosuppressive tumor microenvironment. While we cannot exclude a role of B7-H3 in MDSC differentiation, B7-H3 can also be expressed by MDSCs and contribute to CD8-T-cell inhibition and tumor progression [49-52].

While clinical trials evaluating PD-L1/PD-1 inhibitors in pediatric sarcoma have been unsuccessful, B7-H3 has become a popular target for new, targeted therapies [53]. Antibody-drug conjugates and CAR-T therapy are currently evaluated in clinical trials and are poised to positively change the therapeutic landscape of childhood cancers [54-56]. Our work provides novel mechanistic insights into the role of B7-H3 in tumor immune evasion and RMS progression. A complete characterization of B7-H3 function and regulation will pave the way for developing new B7-H3-based immunotherapies for the treatment of RMS.

\section{Conclusions}

While clinical trials evaluating PD-L1/PD-1 inhibitors in pediatric sarcoma have been unsuccessful, B7-H3 has become a popular target for new, targeted therapies [49]. Antibodydrug conjugates and CAR-T therapy are currently being evaluated in clinical trials and are poised to positively change the therapeutic landscape of childhood cancers [50-52]. Our work provides novel mechanistic insights on the role of $\mathrm{B} 7-\mathrm{H} 3$ in tumor immune evasion and RMS progression. A complete characterization of the $\mathrm{B} 7-\mathrm{H} 3$ functions and regulations will pave the way for developing new B7-H3-based immunotherapies for the treatment of RMS.

Supplementary Materials: The following are available online at https:/ /www.mdpi.com/article/ 10.3390 / cancers13184528/s1, Table S1. Normalized protein abundance (expressed in NSAF values) in RMS and normal muscle cell lines; Table S2. List of proteins identified as cell-surface proteins (GO:00005886); Table S3. List of cell-surface proteins upregulated by 2-fold in RMS compared to normal muscle; Table S4. List of cell-surface proteins upregulated by 2-fold in fusion-negative 
RMS compared to normal muscle; Table S5. List of cell-surface proteins upregulated by 2-fold in fusion-positive RMS compared to normal muscle; Table S6. List of cell-surface proteins from Table S4 upregulated by 2-fold in RMS at the RNA level; Table S7. List of cell-surface proteins from Table S5 upregulated by 2-fold in fusion-negative RMS at the RNA level; Table S8. List of cell-surface proteins from Table S6 upregulated by 2-fold in fusion-positive RMS at the RNA level; Table S9. Normal tissue median RNA expression of RMS-enriched cell-surface proteins; Table S10. Normal tissue median protein expression of RMS-enriched cell-surface proteins; Table S11. B7-H3 tissue expression in RMS specimens and association with clinicopathological features; Table S12. Correlation analysis of B7-H3 expression with immune cell abundance in RMS tumors; Figure S1. Comparison of cellsurface protein repertoires in RMS and normal muscle; Figure S2. Gene enrichment analysis for RMS-enriched cell-surface proteins; Figure S3. Validation of antibody specificity for B7-H3 tissue staining.

Author Contributions: R.R.L., Y.K., and E.B., performed all the experiments. R.R.L. and F.L. designed the experiments and interpreted the data. D.A.P. and P.J.H. performed the cell surface capturing for the RH36, RH18, and RH41 cells. C.M.C. and B.J.M. performed the mass spectrometry and proteomic data analyses. L.W. performed the RNA-seq analysis. P.C.G., M.E.A., and C.F.G. provided the clinical input, data abstraction, and access to the tumor tissue specimens. J.C. reviewed the pathology cases and performed the B7-H3 H-scoring. H.D. provided technical support for the T-cell cytotoxic assays and immune cell analysis. All the authors reviewed and edited the manuscript. F.L. conceptualized and directed the study. All authors have read and agreed to the published version of the manuscript.

Funding: This research was funded by Hyundai on Wheels (C.G. and P.G.); Rein in Sarcoma (F.L., P.G., and H.D.); a departmental startup grant (F.L.); and generous benefactors.

Institutional Review Board Statement: This study was conducted according to the guidelines of the Declaration of Helsinki and approved by the Institutional Review Board of Mayo Clinic (16-006956, October 2016; 19-012426, January 2020).

Informed Consent Statement: Informed consent for use of the biospecimens and data was obtained from all the subjects involved in this study.

Data Availability Statement: All data presented here are available in the Supplementary Materials.

Conflicts of Interest: The authors declare no potential conflict of interest.

\section{References}

1. Davis, R.J.; D'Cruz, C.M.; Lovell, A.M.; Biegel, A.J.; Barr, F.G. Fusion of PAX7 to FKHR by the Variant t(1;13)(p36;q14) Translocation in Alveolar Rhabdomyosarcoma. Cancer Res. 1994, 54, 2869-2872.

2. Barr, F.G.; Galili, N.; Holick, J.; Biegel, J.A.; Rovera, G.; Emanuel, B.S. Rearrangement of the PAX3 Paired Box Gene in the Paediatric Solid Tumour Alveolar Rhabdomyosarcoma. Nat. Genet. 1993, 3, 113-117. [CrossRef]

3. Skapek, S.X.; Anderson, J.; Barr, F.G.; Bridge, J.A.; Gastier-Foster, J.M.; Parham, D.M.; Rudzinski, E.R.; Triche, T.; Hawkins, D.S. PAX-FOXO1 Fusion Status Drives Unfavorable Outcome for Children with Rhabdomyosarcoma: A Children's Oncology Group Report. Pediatr. Blood Cancer 2013, 60, 1411-1417. [CrossRef]

4. Cao, L.; Yu, Y.; Bilke, S.; Walker, R.L.; Mayeenuddin, L.H.; Azorsa, D.O.; Yang, F.; Pineda, M.; Helman, L.J.; Meltzer, P.S. Genome-Wide Identification of PAX3-FKHR Binding Sites in Rhabdomyosarcoma Reveals Candidate Target Genes Important for Development and Cancer. Cancer Res. 2010, 70, 6497-6508. [CrossRef]

5. Shern, J.F.; Chen, L.; Badgett, T.; Getz, G.; Chmielecki, J.; Mora, J.; Anderson, J.R.; Skapek, S.X.; Barr, F.G.; Meyerson, M.; et al. Comprehensive Genomic Analysis of Rhabdomyosarcoma Reveals a Landscape of Alterations Affecting a Common Genetic Axis in Fusion-Positive and Fusion-Negative Tumors. Cancer Discov. 2014, 4, 216-231. [CrossRef] [PubMed]

6. Crist, W.; Gehan, A.E.; Ragab, A.H.; Dickman, P.S.; Donaldson, S.S.; Fryer, C.; Hammond, D.; Hays, D.M.; Herrmann, J.; Heyn, R. The Third Intergroup Rhabdomyosarcoma Study. J. Clin. Oncol. 1995, 13, 610-630. [CrossRef]

7. Maurer, H.M.; Beltangady, M.; Gehan, E.A.; Crist, W.; Hammond, D.; Hays, D.M.; Heyn, R.; Lawrence, W.; Newton, W.; Ortega, J.; et al. The Intergroup Rhabdomyosarcoma Study-I. A Final Report. Cancer 1988, 61, 209-220. [CrossRef]

8. Maurer, H.M.; Gehan, E.A.; Beltangady, M.; Crist, W.; Dickman, P.S.; Donaldson, S.S.; Fryer, C.; Hammond, D.; Hays, D.M.; Herrmann, J.; et al. The Intergroup Rhabdomyosarcoma Study-II. Cancer 1993, 71, 1904-1922. [CrossRef]

9. Punyko, J.A.; Mertens, A.C.; Gurney, J.G.; Yasui, Y.; Donaldson, S.S.; Rodeberg, D.A.; Raney, R.B.; Stovall, M.; Sklar, C.A.; Robison, L.L.; et al. Long-Term Medical Effects of Childhood and Adolescent Rhabdomyosarcoma: A Report from the Childhood Cancer Survivor Study. Pediatr. Blood Cancer 2005, 44, 643-653. [CrossRef] [PubMed] 
10. Reulen, R.C.; Winter, D.L.; Frobisher, C.; Lancashire, E.R.; Stiller, C.A.; Jenney, M.E.; Skinner, R.; Stevens, M.C.; Hawkins, M.M.; British Childhood Cancer Survivor Study Steering Group. Long-term Cause-Specific Mortality among Survivors of Childhood Cancer. JAMA 2010, 304, 172-179. [CrossRef] [PubMed]

11. Lu, R.-M.; Hwang, Y.-C.; Liu, I.-J.; Lee, C.-C.; Tsai, H.-Z.; Li, H.-J.; Wu, H.-C. Development of Therapeutic Antibodies for the Treatment of Diseases. J. Biomed. Sci. 2020, 27, 1-30. [CrossRef]

12. Leung, K.K.; Wilson, G.M.; Kirkemo, L.L.; Riley, N.M.; Coon, J.J.; Wells, J.A. Broad and Thematic Remodeling of the Surfaceome and Glycoproteome on Isogenic Cells Transformed with Driving Proliferative Oncogenes. Proc. Natl. Acad. Sci. USA 2020, 117, 7764-7775. [CrossRef]

13. Chen, W.; Mou, K.Y.; Solomon, P.; Aggarwal, R.; Leung, K.K.; Wells, J.A. Large Remodeling of the Myc-Induced Cell Surface Proteome in B Cells and Prostate Cells Creates New Opportunities for Immunotherapy. Proc. Natl. Acad. Sci. USA 2021, 118. [CrossRef]

14. Martinko, A.J.; Truillet, C.; Julien, O.; Diaz, E.J.; Horlbeck, A.M.; Whiteley, G.; Blonder, J.; Weissman, J.S.; Bandyopadhyay, S.; Evans, M.J.; et al. Targeting RAS-Driven Human Cancer Cells with Antibodies to Upregulated and Essential Cell-Surface Proteins. eLife 2018, 7. [CrossRef]

15. Nesvizhskii, A.I.; Keller, A.; Kolker, E.; Aebersold, R. A Statistical Model for Identifying Proteins by Tandem Mass Spectrometry. Anal. Chem. 2003, 75, 4646-4658. [CrossRef] [PubMed]

16. Deng, N.; Li, Z.; Pan, C.; Duan, H. freeQuant: A Mass Spectrometry Label-Free Quantification Software Tool for Complex Proteome Analysis. Sci. World J. 2015, 2015, 1-11. [CrossRef]

17. Lowerison, M.; Huang, C.; Lucien, F.; Chen, S.; Song, P. Ultrasound Localization Microscopy of Renal Tumor Xenografts in Chicken Embryo is Correlated to Hypoxia. Sci. Rep. 2020, 10, 1-13. [CrossRef] [PubMed]

18. Jiang, L.; Wang, M.; Lin, S.; Jian, R.; Li, X.; Chan, J.; Dong, G.; Fang, H.; Robinson, A.E.; Snyder, M.P.; et al. A Quantitative Proteome Map of the Human Body. Cell 2020, 183, 269-283.e19. [CrossRef]

19. Bonifant, C.; Jackson, H.J.; Brentjens, R.J.; Curran, K.J. Toxicity and Management in CAR T-Cell Therapy. Mol. Ther.-Oncol. 2016, 3, 16011. [CrossRef] [PubMed]

20. Uhlén, M.; Hallström, B.M.; Lindskog, C.; Mardinoglu, A.; Pontén, F.; Nielsen, J. Transcriptomics Resources of Human Tissues and Organs. Mol. Syst. Biol. 2016, 12, 862. [CrossRef]

21. Mackay, M.; Afshinnekoo, E.; Rub, J.; Hassan, C.; Khunte, M.; Baskaran, N.; Owens, B.; Liu, L.; Roboz, G.J.; Guzman, M.L.; et al. The Therapeutic Landscape for Cells Engineered with Chimeric Antigen Receptors. Nat. Biotechnol. 2020, 38, 233-244. [CrossRef] [PubMed]

22. Hegde, M.; Joseph, S.K.; Pashankar, F.; DeRenzo, C.; Sanber, K.; Navai, S.; Byrd, T.T.; Hicks, J.; Xu, M.L.; Gerken, C.; et al. Tumor Response and Endogenous Immune Reactivity after Administration of HER2 CAR T Cells in a Child with Metastatic Rhabdomyosarcoma. Nat. Commun. 2020, 11, 1-15. [CrossRef] [PubMed]

23. Ni, L.; Dong, C. New B7 Family Checkpoints in Human Cancers. Mol. Cancer Ther. 2017, 16, 1203-1211. [CrossRef] [PubMed]

24. Kontos, F.; Michelakos, T.; Kurokawa, T.; Sadagopan, A.; Schwab, J.H.; Ferrone, C.R.; Ferrone, S. B7-H3: An Attractive Target for Antibody-based Immunotherapy. Clin. Cancer Res. 2020, 27, 1227-1235. [CrossRef] [PubMed]

25. Chapoval, A.I.; Ni, J.; Lau, J.S.; Wilcox, R.A.; Flies, D.B.; Liu, D.; Dong, H.; Sica, G.L.; Zhu, G.; Tamada, K.; et al. B7-H3: A Costimulatory Molecule for T Cell Activation and IFN- $\gamma$ Production. Nat. Immunol. 2001, 2, 269-274. [CrossRef]

26. Lee, Y.-H.; Martin-Orozco, N.; Zheng, P.; Li, J.; Zhang, P.; Tan, H.; Park, H.J.; Jeong, M.; Chang, S.H.; Kim, B.-S.; et al. Inhibition of the B7-H3 Immune Checkpoint Limits Tumor Growth by Enhancing Cytotoxic Lymphocyte Function. Cell Res. 2017, 27, 1034-1045. [CrossRef]

27. Finotello, F.; Mayer, C.; Plattner, C.; Laschober, G.; Rieder, D.; Hackl, H.; Krogsdam, A.; Loncova, Z.; Posch, W.; Wilflingseder, D.; et al. Molecular and Pharmacological Modulators of the Tumor Immune Contexture Revealed by Deconvolution of RNA-seq Data. Genome Med. 2019, 11, 1-20. [CrossRef]

28. Wollscheid, B.; Bausch-Fluck, D.; Henderson, C.; O’Brien, R.; Bibel, M.; Schiess, R.; Aebersold, R.; Watts, J.D. Mass-Spectrometric Identification and Relative Quantification of N-Linked Cell Surface Glycoproteins. Nat. Biotechnol. 2009, 27, 378-386. [CrossRef]

29. Nix, M.A.; Mandal, K.; Geng, H.; Paranjape, N.; Lin, Y.-H.T.; Rivera, J.M.; Marcoulis, M.; White, K.L.; Whitman, J.D.; Bapat, S.P.; et al. Surface Proteomics Reveals CD72 as a Target for In Vitro-Evolved Nanobody-Based CAR-T Cells in KMT2A/MLL1Rearranged B-ALL. Cancer Discov. 2021. [CrossRef]

30. Heider, M.; Eichner, R.; Stroh, J.; Morath, V.; Kuisl, A.; Zecha, J.; Lawatscheck, J.; Baek, K.; Garz, A.-K.; Rudelius, M.; et al. The IMiD Target CRBN Determines HSP90 Activity Toward Transmembrane Proteins Essential in Multiple Myeloma. Mol. Cell 2021, 81, 1170-1186.e10. [CrossRef]

31. Lee, J.; Bangayan, N.J.; Chai, T.; Smith, B.A.; Pariva, T.E.; Yun, S.; Vashisht, A.; Zhang, Q.; Park, J.W.; Corey, E.; et al. Systemic Surfaceome Profiling Identifies Target Antigens for Immune-Based Therapy in Subtypes of Advanced Prostate Cancer. Proc. Natl. Acad. Sci. USA 2018, 115, E4473-E4482. [CrossRef]

32. Davicioni, E.; Finckenstein, F.G.; Shahbazian, V.; Buckley, J.D.; Triche, T.J.; Anderson, M.J. Identification of a PAX-FKHR Gene Expression Signature that Defines Molecular Classes and Determines the Prognosis of Alveolar Rhabdomyosarcomas. Cancer Res. 2006, 66, 6936-6946. [CrossRef]

33. Tang, Q.; Lu, J.; Zou, C.; Shao, Y.; Chen, Y.; Narala, S.; Fang, H.; Xu, H.; Wang, J.; Shen, J.; et al. CDH4 is a Novel Determinant of Osteosarcoma Tumorigenesis and Metastasis. Oncogene 2018, 37, 3617-3630. [CrossRef] [PubMed] 
34. Ceresa, D.; Alessandrini, F.; Bosio, L.; Marubbi, D.; Reverberi, D.; Malatesta, P.; Appolloni, I. Cdh4 Down-Regulation Impairs in Vivo Infiltration and Malignancy in Patients Derived Glioblastoma Cells. Int. J. Mol. Sci. 2019, 20, 4028. [CrossRef]

35. Kucharczak, J.; Charrasse, S.; Comunale, F.; Zappulla, J.; Robert, B.; Teulon-Navarro, I.; Pèlegrin, A.; Gauthier-Rouviere, C. R-Cadherin Expression Inhibits Myogenesis and Induces Myoblast Transformation via Rac1 GTPase. Cancer Res. 2008, 68, 6559-6568. [CrossRef] [PubMed]

36. Boyd, A.W.; Bartlett, P.F.; Lackmann, M. Therapeutic Targeting of EPH Receptors and Their Ligands. Nat. Rev. Drug Discov. 2013, 13, 39-62. [CrossRef] [PubMed]

37. Klein, R. Eph/Ephrin Signalling during Development. Development 2012, 139, 4105-4109. [CrossRef] [PubMed]

38. Wang, B. Cancer Cells Exploit the Eph-Ephrin System to Promote Invasion and Metastasis: Tales of Unwitting Partners. Sci. Signal. 2011, 4, pe28. [CrossRef]

39. Giaginis, C.; Tsoukalas, N.; Bournakis, E.; Alexandrou, P.; Kavantzas, N.; Patsouris, E.; Theocharis, S. Ephrin (Eph) receptor A1, A4, A5 and A7 Expression in Human Non-Small Cell Lung Carcinoma: Associations with Clinicopathological Parameters, Tumor Proliferative Capacity and Patients' Survival. BMC Clin. Pathol. 2014, 14, 8. [CrossRef]

40. Li, R.; Jin, M.; Sun, Y.; Jiang, A.; Wu, Y.; Li, C.; Yan, H.; Jin, H. Knockdown of Ephrin Receptor A7 Suppresses the Proliferation and Metastasis of A549 Human Lung Cancer Cells. Mol. Med. Rep. 2016, 13, 3190-3196. [CrossRef]

41. Di, W.; Weinan, X.; Xin, L.; Zhiwei, Y.; Xinyue, G.; Jinxue, T.; Mingqi, L. Long Noncoding RNA SNHG14 Facilitates Colorectal Cancer Metastasis through Targeting EZH2-Regulated EPHA7. Cell Death Dis. 2019, 10, 1-13. [CrossRef] [PubMed]

42. Gabrych, A.; Pẹksa, R.; Kunc, M.; Krawczyk, M.; Izycka-Swieszewska, E.; Biernat, W.; Bień, E. The PD-L1/PD-1 Axis Expression on Tumor-Infiltrating Immune Cells and Tumor Cells in Pediatric Rhabdomyosarcoma. Pathol. Res. Pract. 2019, $215,152700$. [CrossRef] [PubMed]

43. Bertolini, G.; Bergamaschi, L.; Ferrari, A.; Renne, S.L.; Collini, P.; Gardelli, C.; Barisella, M.; Centonze, G.; Chiaravalli, S.; Paolino, C.; et al. PD-L1 Assessment in Pediatric Rhabdomyosarcoma: A Pilot Study. BMC Cancer 2018, 18, 652. [CrossRef] [PubMed]

44. Flem-Karlsen, K.; Fodstad, O.; Tan, M.; Nunes-Xavier, C.E. B7-H3 in Cancer-Beyond Immune Regulation. Trends Cancer 2018, 4, 401-404. [CrossRef] [PubMed]

45. Li, G.; Quan, Y.; Che, F.; Wang, L. B7-H3 in Tumors: Friend or Foe for Tumor Immunity? Cancer Chemother. Pharmacol. 2018, 81, 245-253. [CrossRef]

46. Mao, Y.; Chen, L.; Wang, F.; Zhu, D.; Ge, X.; Hua, D.; Sun, J. Cancer Cell-Expressed B7-H3 Regulates the Differentiation of Tumor-Associated Macrophages in Human Colorectal Carcinoma. Oncol. Lett. 2017, 14, 6177-6183. [CrossRef]

47. Kang, F.-B.; Wang, L.; Li, N.; Zhang, Y.-G.; Sun, D.-X. Hepatocellular Carcinomas Promote Tumor-Associated Macrophage M2-Polarization via Increased B7-H3 Expression. Oncol. Rep. 2014, 33, 274-282. [CrossRef]

48. Yim, J.; Koh, J.; Kim, S.; Song, S.G.; Ahn, H.K.; Kim, A.Y.; Jeon, Y.K.; Chung, D.H. Effects of B7-H3 Expression on TumourInfiltrating Immune Cells and Clinicopathological Characteristics in Non-Small-Cell Lung Cancer. Eur. J. Cancer 2020, $133,74-85$. [CrossRef]

49. Zhang, G.; Huang, H.; Zhu, Y.; Yu, G.; Gao, X.; Xu, Y.; Liu, C.; Hou, J.; Zhang, X. A Novel Subset of B7-H3+CD14+HLADR-/Lowmyeloid-Derived Suppressor Cells are Associated with Progression of Human NSCLC. OncoImmunology 2015, 4, e977164. [CrossRef]

50. Baumann, T.; Dunkel, A.; Schmid, C.; Schmitt, S.; Hiltensperger, M.; Lohr, K.; Laketa, V.; Donakonda, S.; Ahting, U.; LorenzDepiereux, B.; et al. Regulatory Myeloid Cells Paralyze T Cells through Cell-Cell Transfer of the Metabolite Methylglyoxal. Nat. Immunol. 2020, 21, 555-566. [CrossRef]

51. Si, Y.; Merz, S.F.; Jansen, P.; Wang, B.; Bruderek, K.; Altenhoff, P.; Mattheis, S.; Lang, S.; Gunzer, M.; Klode, J.; et al. Multidimensional Imaging Provides Evidence for Down-Regulation of T Cell Effector Function by MDSC in Human Cancer Tissue. Sci. Immunol. 2019, 4, eaaw9159. [CrossRef] [PubMed]

52. Yang, S.; Wei, W.; Zhao, Q. B7-H3, a Checkpoint Molecule, as a Target for Cancer Immunotherapy. Int. J. Biol. Sci. 2020, 16, 1767-1773. [CrossRef]

53. Majzner, R.G.; Theruvath, J.L.; Nellan, A.; Heitzeneder, S.; Cui, Y.; Mount, C.W.; Rietberg, S.P.; Linde, M.H.; Xu, P.; Rota, C.; et al. CAR T Cells Targeting B7-H3, a Pan-Cancer Antigen, Demonstrate Potent Preclinical Activity Against Pediatric Solid Tumors and Brain Tumors. Clin. Cancer Res. 2019, 25, 2560-2574. [CrossRef] [PubMed]

54. Theruvath, J.; Sotillo, E.; Mount, C.W.; Graef, C.M.; Delaidelli, A.; Heitzeneder, S.; Labanieh, L.; Dhingra, S.; Leruste, A.; Majzner, R.G.; et al. Locoregionally Administered B7-H3-Targeted CAR T Cells for Treatment of Atypical Teratoid/Rhabdoid Tumors. Nat. Med. 2020, 26, 712-719. [CrossRef] [PubMed]

55. Scribner, J.A.; Brown, J.G.; Son, T.; Chiechi, M.; Li, P.; Sharma, S.; Li, H.; De Costa, A.; Li, Y.; Chen, Y.; et al. Preclinical Development of MGC018, a Duocarmycin-Based Antibody-Drug Conjugate Targeting B7-H3 for Solid Cancer. Mol. Cancer Ther. 2020, 19, 2235-2244. [CrossRef]

56. Love, I.M.; Huber, W.; Anders, S. Moderated Estimation of Fold Change and Dispersion for RNA-seq Data with DESeq2. Genome Biol. 2014, 15, 550. [CrossRef] 